\title{
Kavun çekirdeği pirolizine ait kinetik parametrelerin ve termodinamik özelliklerin belirlenmesi
}

\section{Determination of kinetic parameters and thermodynamic properties of melon seed pyrolysis}

\author{
Korkut Açıkalın",* (iD, Gözde Gözke² \\ ${ }^{l}$ Yalova Üniversitesi, Enerji Sistemleri Mühendisliği Bölümü, 77200, Yalova Türkiye \\ ${ }^{2}$ Yalova Üniversitesi, Kimya Mühendisliği Bölümü, 77200, Yalova, Türkiye
}

\begin{abstract}
Özet
$\mathrm{Bu}$ çalışmanın amacı, kavun çekirdeği pirolizinin davranışını incelemek ve kinetik parametreleri ile termodinamik özelliklerini hesaplamaktır. Termogravimetrik analiz deneyleri azot atmosferinde çevre sicaklığından $800^{\circ} \mathrm{C}^{\prime}$ ye $5,10,20$ ve $40^{\circ} \mathrm{C} / \mathrm{dk} 1$ sitma hızlarında çalışılmıştır. Piroliz prosesinin, ikinci ve üçüncü basamakları aktif piroliz basamağı olan dört basamakta gerçekleştiği tespit edilmiştir. Kinetik hesaplamalar model içermeyen Flynn-Wall-Ozawa, Kissinger-Akahira-Sunose, Starink ve model bazlı Coats-Redfern yöntemi ile gerçekleştirilmiştir. İkinci ve üçüncü basamaklara ait görünen aktivasyon enerjisi değerlerinin sırasıyla, 123.9215.5 ve $141.9-234.2 \mathrm{~kJ} / \mathrm{mol}$ aralıklarında olduğu hesaplanmıştır. Coats-Redfern yöntemi, ikinci ve üçüncü basamakların sirasiyla F1.65 ve D5 reaksiyon mekanizmalarına uyduğunu ortaya koymuştur. Ayrıca, $10^{\circ} \mathrm{C} / \mathrm{dk}$ isıtma hızında gerçekleştirilen piroliz prosesinin aktif piroliz basamakları için, model içermeyen kinetik yöntemlerden hesaplanan sonuçlar kullanılarak entalpi, entropi ve Gibbs enerji değişimleri hesaplanmıştır. Mevcut çalışmada elde edilen sonuçlar, kavun çekirdeği piroliz proseslerinin tasarlanmasında gerekli olan bilgileri sağlamada faydalı olacaktır.
\end{abstract}

Anahtar kelimeler: Kavun çekirdeği, Piroliz davranışı, Piroliz kinetiği, Termodinamik özellikler

\section{Giriş}

Nüfus artışına bağlı olarak artan enerji tüketimi göz önüne alındığında, küresel enerji ihtiyacının 2040 senesine kadar \%25'ten fazla artmas beklenmektedir [1]. Fosil yakıtlar hala en sık kullanılan enerji kaynağı olmakla birlikte hızla tükenmektedirler. Bununla birlikte, petrol bazlı yakıtlar yüksek miktarda karbondioksit ile $\mathrm{SO}_{\mathrm{x}}$ ve $\mathrm{NO}_{\mathrm{x}}$ gibi diğer kirleticilerin salınımına da yol açarak iklim değişikliğine ve çevresel bozulmaya neden olmaktadır [2,3].

Biyokütle doğada bol miktarda bulunan, temiz ve yenilenebilir bir enerji kaynağıdır ve biyokütle enerjisinin geliştirilmesi ve kullanımı dünya çapında giderek artan bir şekilde önem kazanmaktadır [4]. Biyokütle, yakıt ve kimyasalların sağlanmasında fosil yakıt kaynaklarıyla benzerliği nedeniyle umut verici olmasının yanı sıra düşük

\begin{abstract}
The aim of this study is to examine the behaviour of melon seed pyrolysis and to calculate its kinetic parameters along with thermodynamic properties. The thermogravimetric analysis experiments were conducted from ambient temperature to $800^{\circ} \mathrm{C}$ under nitrogen atmosphere at the heating rates of $5,10,20$ and $40^{\circ} \mathrm{C} / \mathrm{min}$. It was determined that the pyrolysis process underwent through four stages where the second and third stages were the active pyrolysis stages. Kinetic calculations were carried out using modelfree Flynn-Wall-Ozawa, Kissinger-Akahira-Sunose, Starink and model-based Coats-Redfern methods. The apparent activation energy values of the second and third stages were calculated to be in the ranges of 123.9-215.5 and 141.9-234.2 kJ/mol, respectively. The Coats-Redfern method demonstrated that the second and third stages fit the reaction mechanisms of $\mathrm{F} 1.65$ and D5, respectively. Moreover, the enthalpy, entropy and Gibbs energy changes of the active pyrolysis stages performed at $10^{\circ} \mathrm{C} / \mathrm{min}$ heating rate were determined using the results calculated from the model-free kinetic methods. The results obtained in the present study will be useful to provide necessary information needed for the design of melon seed pyrolysis processes.
\end{abstract}

Keywords: Melon seed, Pyrolysis behaviour, Pyrolysis kinetics, Thermodynamic properties

kükürt içeriğine sahip olması ve çevreyle dost olan karbonca nötr bir malzeme olması nedeniyle de önemli bir alternatiftir [5]. Bu nedenle, biyokütle kaynaklı enerji, yakın gelecekte sürdürülebilir kalkınma sağlama potansiyeline sahip en gelecek vadeden yenilenebilir enerji kaynaklarından biri olarak kabul edilmektedir [6]. Biyokütle kaynakları arasında odun ve odun atıkları, tarımsal ürünler ve bunların atık yan ürünleri, belediye katı atıkları, hayvansal atıklar, gıda işlemeden kaynaklanan atıklar ve su bitkileri ile algler bulunmaktadır [7]. Bunlar arasında gıda atıkları önemli bir yer tutmaktadır [8].

Türkiye, birçok tarım ürünün yetişmesi için uygun bir iklime ve toprak yapısına sahiptir. Bu tarım ürünlerinden biri olan kavun (Cucumis melo L.), yüksek ekonomik öneme sahiptir. 2019 yılı verilerine göre kavun Türkiye'de 1777059

\footnotetext{
* Sorumlu yazar / Corresponding author, e-posta / e-mail: korkut.acikalin@yalova.edu.tr (K. Açıkalın) Geliș / Recieved: 05.04.2021 Kabul / Accepted: 27.05.2021 Yayımlanma / Published: 27.07.2021 doi: 10.28948/ngmuh.910277
} 
ton üretilmiştir ve Türkiye, Çin'den sonra gelen en büyük üretici konumundadır [9]. Üretimin $\% 41$ oranla büyük bölümü İç Anadolu Bölgesi'ne yoğunlaşmıştır [10]. Kavun üretiminin miktarıyla orantılı olarak kavun çekirdeği biyokütle atık madde olarak ortaya çıkmaktadır. Kavun çekirdeği (Citrullus colocynthis L.) cucurbitaceae familyasından Citrullus cinsine aittir ve $\% 53$ oranında yağ, $\% 28$ oranında protein içermektedir [11]. Kavun çekirdeğinden elde edilen yağ, başta evsel tüketim olmak üzere, tıbbi amaçlarla ve biyodizel, sabun, deterjan, margarin üretimi gibi endüstriyel uygulamalarda da kullanılmaktadır [12]. Türkiye'de ise kavun çekirdeği, daha çok atıştırmalık ve sübye olarak tüketilmesinin dişında büyük oranda bitkisel atık olarak kalmaktadır [13, 14]. Bunların yanı sıra, gıda ürünlerinin besin değerini arttırmak ve glutensiz beslenme sağlamak amacıyla, öğütülmüş kavun çekirdeklerinin kullanıldığı çalışmalar da mevcuttur $[8,15,16]$.

Piroliz, bitkisel atıkların biyoyağ, yanıcı gaz ürün ve karbonca zengin biyokömür gibi malzemelere dönüştürülmesi için uygun 1sıl bir prosestir [17]. Biyokütlenin 1sıl ayrışma kinetiği, biyokütlenin enerjiye ve ürünlere dönüştürülmesine yönelik termokimyasal işlemlerin tasarımında anahtar bir bileşendir [18]. Termogravimetrik analiz (TGA), biyokütle pirolizi için 1sıl dönüşüm davranışı ve kinetik modellemeyi belirlemede kullanılan önemli bir tekniktir. Biyokütlenin 1sıl dönüşüm sistemlerinin tasarlanması için termogravimetrik analizden elde edilen verilerin kullanılarak kinetiğinin incelenmesi gereklidir. İzotermal olmayan, bir başka deyişle sıcaklığın belirlenen sürelerde arttırıldığı koşullarda, termogravimetrik analizden elde edilen veriler, kinetik model bazlı ve model içermeyen yöntemler kullanılarak incelenebilir. Katı hal ısıl bozunma verilerinin analiz edilerek kinetik parametrelerin hesaplanabilmesi için çok sayıda kinetik yöntem geliştirilmiştir [19, 20].

Kavun çekirdeğinin biyoyakıt potansiyeli daha önceki bir çalışmada açıklanmıştır [21]. Yapılan literatür araştırması mevcut çalışmaların kavun çekirdeği kabuğu ile ilgili olduğunu [11, 12, 22]; kavun çekirdeğinin piroliz kinetiği ile ilgili bir çalışmanın ise bulunmadığını ortaya koymuştur. Bu çalışmada, kavun çekirdeklerinin piroliz koşullarında elde edilen termogravimetrik analiz verileri üzerinden kinetik parametrelerinin ve termodinamik özelliklerinin hesaplanması amaçlanmıştır. $\mathrm{Bu}$ bağlamda, aktivasyon enerjisi, gerek eş dönüşümlü model içermeyen yöntemler olan Flynn-Wall-Ozawa (FWO), Kissinger-Akahira-Sunose (KAS), Starink yöntemleri, gerekse model içeren yöntem olan Coats-Redfern yöntemi ile hesaplanmış; reaksiyon mekanizması ve pre-eksponansiyel faktör ise Coats-Redfern yöntemi üzerinden belirlenmiştir. İlgili termodinamik eşitlikler kullanılarak termodinamik özellikler de hesaplanmış ve böylece kavun çekirdeğinin piroliz, süreçlerinin tasarlanabilmesi, geliştirilebilmesi ve optimize edilebilmesi için gerekli olan bir aşama tamamlanmıştır.

\section{Materyal ve metot}

\subsection{Materyal}

Kavunlar, Yalova'daki yerel bir pazardan temin edilmiştir. Kavun kesildikten sonra çıkarılan çekirdekler hava ortamında ve güneş altında 2 hafta boyunca ön kurutma işlemine tabi tutulmuştur. Ön kurutma işlemini takiben öğütülen kavun çekirdekleri eleklerden geçirilerek, 150-250 $\mu \mathrm{m}$ fraksiyon aralığı deneylerde kullanılmak üzere ayrılmıştır. Öğ̈̈tülen ve istenilen parçacık boyutunda fraksiyona ayrılan çekirdekler daha sonra etüvde $105^{\circ} \mathrm{C}$ 'de 24 saat boyunca son kurutma işlemine tabi tutulmuştur. Etüvden çıkarılan numuneler desikatörde soğutulduktan sonra cam amber numune şişelerinde saklanmıştır. Elementel ve ısıl değer analizleri, sirasıyla LECO CHNS932 (ABD) ve IKA C5000 (Almanya) cihazları ile gerçekleştirilmiştir. Kavun çekirdeklerinin elementel analiz, 1sıl değer, ASTM E1131-20 ve ASTM D1102-84-2013'e uygun gerçekleştirilen kısa analiz sonuçları Tablo 1'de verilmektedir.

Tablo 1. Kavun çekirdeği ve bazı diğer biyokütle maddelerin kısa, elementel ve ısıl değer analiz sonuçları

\begin{tabular}{|c|c|c|c|c|c|c|c|}
\hline & $\begin{array}{l}\text { Kavun } \\
\text { çek, }\end{array}$ & $\begin{array}{c}\text { Ceviz } \\
\text { kabuğu }\end{array}$ & $\begin{array}{l}\text { Antep f, } \\
\text { kabuğu }\end{array}$ & $\begin{array}{l}\text { Vişne } \\
\text { sapl }\end{array}$ & $\begin{array}{l}\text { Vişne } \\
\text { posast }\end{array}$ & $\begin{array}{c}\text { Elma } \\
\text { posasl }\end{array}$ & $\begin{array}{l}\text { Hurma } \\
\text { çek, }^{* *}\end{array}$ \\
\hline \multicolumn{8}{|c|}{$\overline{\text { Kisa analiz (\% ăg,) }}$} \\
\hline Nem & 6.57 & 2.57 & 3.71 & 10 & 12.20 & 8.87 & 5.45 \\
\hline Uçucu madde & 75.44 & 78.04 & 77.45 & 67.12 & 67.60 & 81.32 & 78.59 \\
\hline Kül & 1.78 & 0.64 & 0.41 & 2.10 & 2.80 & 3.40 & 2.15 \\
\hline Sabit karbon & $16.21 *$ & 18.75 & 18.43 & 20.78 & 17.40 & 6.41 & 13.81 \\
\hline \multicolumn{8}{|c|}{ Elementel analiz (\% ăg,) } \\
\hline $\mathrm{C}$ & 54.06 & 48.34 & 44.62 & 43.18 & 41.21 & 47.98 & 45.76 \\
\hline $\mathrm{H}$ & 8.60 & 6.16 & 5.81 & 6.32 & 6.41 & 6.65 & 9.59 \\
\hline $\mathrm{O}$ & $31.20 *$ & 44.78 & 49.25 & 49.59 & 50.71 & 37.44 & 44.59 \\
\hline $\mathrm{N}$ & 5.82 & 0.69 & 0.32 & 0.91 & 1.67 & 0.78 & 0.02 \\
\hline S & 0.32 & 0.03 & - & - & - & - & 0.04 \\
\hline $\begin{array}{l}\ddot{U} \text { st istl değer } \\
(M J / k g)\end{array}$ & 23.56 & 17.86 & 17.40 & 16.43 & 15.92 & 22.42 & 18.00 \\
\hline Kaynak & $\begin{array}{c}\mathrm{Bu} \\
\text { çalışma }\end{array}$ & [23] & [24] & [25] & [25] & [26] & [27] \\
\hline
\end{tabular}

${ }^{*}$ Farktan hesaplanmıştır; ${ }^{* *}$ Hint hurması çekirdeğ

\subsection{Termogravimetrik analiz (TGA)}

Kavun çekirdeklerinin izotermal olmayan termogravimetrik analizleri, Yalova Üniversitesi Merkez Laboratuvarı bünyesindeki EXSTAR SII TG/DTA 6300 (Seiko Instruments, Japonya) termogravimerik analiz cihazında, porselen kroze kullanılarak gerçekleştirilmiştir. Her analiz için $4 \mathrm{mg} \pm 0.01 \mathrm{mg}$ numune, ortam sıcaklığından $800^{\circ} \mathrm{C}$ sıcaklığa kadar, $200 \mathrm{~mL} / \mathrm{dk}$ debideki azot atmosferi altında, dört farklı 1sıtma hızında $\left(5,10,20\right.$ ve $\left.40^{\circ} \mathrm{C} / \mathrm{dk}\right)$ 1sıtılmıştır.

\subsection{Kinetik hesaplamalar}

Piroliz işlemi sırasında biyokütleler, çar, uçucu madde ve gazlara dönüşürler [28]:

$$
\text { Biyokütle } \rightarrow \text { çar + (uçucu maddeler + gazlar })
$$

İzotermal olmayan koşullar altında heterojen katı hal kinetik reaksiyonu aşağıdaki şekilde ifade edilebilir [29]:

$$
\frac{d \alpha}{d t}=k(T) f(\alpha)
$$


Burada, $d \alpha / d t$ piroliz reaksiyonu hızı, $f(\alpha)$ reaksiyon modeli (mekanizması) ve $k(T)$ ise sıcaklığa bağlı reaksiyon hız sabitidir. Arrhenius eşitliği, reaksiyon hız sabitinin sıcaklığa bağlılığını açıklamaktadır:

$$
k(T)=A e^{\left(-\frac{E_{a}}{R T}\right)}
$$

Burada, $A, E_{\text {a }}, R$ ve $T$ sirasiyla pre-eksponansiyel faktör, görünen aktivasyon enerjisi, gaz sabiti ve mutlak sıcaklıktır. Denklem (3), Denklem (2)'de yerine koyulursa, Denklem (4) elde edilir:

$$
\frac{d \alpha}{d t}=A e^{\left(-\frac{E_{a}}{R T}\right)} f(\alpha)
$$

Isıtma hızı, $\beta=d T / d t$, izotermal olmayan koşullar için, Denklem (4)'te yerine koyulursa diferansiyel yöntemler için kullanılan genel eşitlik elde edilir.

$$
\frac{d \alpha}{d T}=\frac{A}{\beta} e^{\left(-\frac{E_{a}}{R T}\right)} f(\alpha)
$$

Dönüşüm oranı, $\alpha$, 1sıl olarak bozunan biyokütle oranını temsil eder ve başlangıç kütlesi $\left(m_{\mathrm{i}}\right), t$ zamanındaki kütlesi $\left(m_{\mathrm{t}}\right)$ ve son kütle $\left(m_{\mathrm{f}}\right)$ değeri cinsinden ifade edilir:

$$
\alpha=\frac{m_{i}-m_{t}}{m_{i}-m_{f}}
$$

İntegral yöntemler için kullanılan genel denklem, Denklem (5)'in integralinin alınmasıyla elde edilir [30].

$$
\begin{aligned}
g(\alpha)=\int_{0}^{\alpha} \frac{d \alpha}{f(\alpha)} & =\frac{A}{\beta} \int_{T_{0}}^{T} \exp \left(-\frac{E_{a}}{R T}\right) d T \\
& =\frac{A}{\beta} \int_{0}^{T} \exp \left(-\frac{E_{a}}{R T}\right) d T \\
& =\frac{A E}{\beta R} p(x)
\end{aligned}
$$

Denklem (7)'nin çözümü için, farklı yaklaşımlar ve basitleştirmeler uygulanmıştır. $\mathrm{Bu}$ yaklaşım ve basitleştirmelerin uygulanmasıyla elde edilen ve mevcut çalışmada kullanılan model içermeyen ve model bazlı integral kinetik yöntemler aşağıda verilmektedir.

\subsubsection{Model içermeyen kinetik yöntemler}

Flynn-Wall-Ozawa (FWO) yöntemi

Denklem (7)'nin geliştirilmesiyle elde edilen FWO yönteminin denklemi aşağıda verilmiştir [31].

$$
\ln \beta=\ln \frac{A E_{a}}{R g(\alpha)}-5,331-1,052 \frac{E_{a}}{R T}
$$

FWO yönteminde, 1/T'ye karşılık ln $\beta$ grafiği çizildiğinde, eğimden $E_{\mathrm{a}}$ değeri hesaplanabilir.

\section{Kissinger-Akahira-Sunose (KAS) yöntemi}

Model içermeyen diğer bir kinetik yöntem KAS yöntemidir ve denklemi aşağıdaki şekilde tanımlanır [32]:

$$
\ln \frac{\beta}{T^{2}}=\ln \left(\frac{A R}{E_{a} g(\alpha)}\right)-\frac{E_{a}}{R T}
$$

KAS yöntemi, 1/T'ye karşılık ln $\beta / T^{2}$ grafiğindeki doğrusal çizginin eğiminden $E_{\mathrm{a}}$ değerinin hesaplanmasını mümkün k1lar.

\section{Starink yöntemi}

Starink yönteminin doğrusal denklemi aşağıda verilmiştir [33].

$$
\ln \frac{\beta}{T^{1,92}}=-1,0008 \frac{E_{a}}{R T}+\text { sabit }
$$

Starink yönteminde $E_{\mathrm{a}}$ değeri, 1/Tye karşı $\ln \beta / T^{1,92}$ grafiği çizilerek elde edilen doğrusal çizginin eğiminden hesaplanabilir.

\subsubsection{Model bazll kinetik yöntem}

Coats-Redfern yöntemi

Coats-Redfern yöntemi model bazlı bir integral kinetik yöntemidir ve yöntemde kullanılan doğrusal denklem aşağıda verilmiştir [34].

$$
\ln \left(\frac{g(\alpha)}{T^{2}}\right)=\ln \left(\frac{A R}{\beta E_{a}}\right)-\frac{E_{a}}{R T}
$$

$\mathrm{Bu}$ yöntemde, 1/T'ye karşılık çizilen $\ln \left(\frac{g(\alpha)}{T^{2}}\right)$ grafiklerinde elde edilen doğrunun eğiminden ve kayımından sırasıyla, $E_{\mathrm{a}}$ ve $A$ değerleri hesaplanabilir. Ancak, Denklem (11)'den görüldüğü üzere hesaplanacak değerler $g(\alpha)$ 'ya, dolayısıyla, reaksiyon mekanizmasının seçimine bağlıdır. Katı hal ısıl bozunmasını temsilde kullanılabilen birçok reaksiyon mekanizması ve bu mekanizmaların $g(\alpha)$ ifadeleri Tablo 2'de verilmiştir.

\subsection{Termodinamik özelliklerin hesaplanması}

Entalpi değişimi $(\Delta H)$, Entropi değişimi $(\Delta S)$ ve Gibbs enerji değişimi $(\Delta G)$ değerlerinin hesaplanması amacıyla aşağıdaki denklemler kullanılmıştır [41].

$$
\begin{gathered}
A=\beta E_{\alpha} \exp \left(\frac{E_{\alpha}}{R T_{m}}\right) /\left(R T_{m}^{2}\right) \\
\Delta H=E_{\alpha}-R T \\
\Delta G=E_{\alpha}+R T_{m} \ln \left(\frac{K_{B} T_{m}}{h A}\right) \\
\Delta S=\frac{\Delta H-\Delta G}{T_{m}}
\end{gathered}
$$

Burada:

$K_{\mathrm{B}}($ Boltzmann sabiti $)=1.381 \times 10^{-23} \mathrm{~J} / \mathrm{K}$, $h($ Plank sabiti $)=6.626 \times 10^{-34} \mathrm{~J} . \mathrm{s}$ $T_{\mathrm{m}}$ : DTG pik sıcaklığıdır. 
Tablo 2. Katı hal 1sil bozunması reaksiyon mekanizmaları

\begin{tabular}{|c|c|c|c|}
\hline No & $\begin{array}{l}\text { Reaksiyon } \\
\text { mekanizması }\end{array}$ & $g(\alpha)$ & Kaynak \\
\hline \multicolumn{4}{|c|}{ n. dereceden kimyasal reaksiyon modelleri } \\
\hline 1 & $n=0(\mathrm{~F} 0)$ & $\alpha$ & [35] \\
\hline 2 & $n=0.5(\mathrm{~F} 0.5)$ & $2\left[1-(1-\alpha)^{1 / 2}\right]$ & [36] \\
\hline 3 & $n=1(\mathrm{~F} 1)$ & $-\ln (1-\alpha)$ & [35] \\
\hline 4 & $n=1.5(\mathrm{~F} 1.5)$ & $2\left[(1-\alpha)^{-1 / 2}-1\right]$ & [37] \\
\hline 5 & $n=2(\mathrm{~F} 2)$ & $(1-\alpha)^{-1}-1$ & [38] \\
\hline 6 & $n=2.5(\mathrm{~F} 2.5)$ & $2 / 3\left[(1-\alpha)^{-3 / 2}-1\right]$ & [36] \\
\hline 7 & $n=3$ (F3) & {$\left[(1-\alpha)^{-2}-1\right] / 2$} & [37] \\
\hline 8 & $n=3.5(\mathrm{~F} 3.5)$ & $2 / 5\left[(1-\alpha)^{-5 / 2}-1\right]$ & [36] \\
\hline 9 & $n=4(\mathrm{~F} 4)$ & {$\left[(1-\alpha)^{-3}-1\right] / 3$} & [36] \\
\hline \multicolumn{4}{|c|}{ Dif. (difüzyon) modelleri } \\
\hline 10 & 1-B dif. (D1) & $\alpha^{2}$ & [35] \\
\hline 11 & 2-B dif. (D2) & $((1-\alpha) \ln (1-\alpha))+\alpha$ & [35] \\
\hline 12 & 3-B dif. (Jander - D3) & $\left(1-(1-\alpha)^{\frac{1}{3}}\right)^{2}$ & [35] \\
\hline 13 & $\begin{array}{l}\text { 3-B dif. (Ginstling- } \\
\text { Brounshtein - D4) }\end{array}$ & $1-\frac{2}{3} \alpha-(1-\alpha)^{2 / 3}$ & [38] \\
\hline 14 & $\begin{array}{l}\text { 3-B dif. (Zhuravlev- } \\
\text { Lesokhin-Tempelman } \\
\text { - D5) }\end{array}$ & {$\left[(1-\alpha)^{-\frac{1}{3}}-1\right]^{2}$} & [38] \\
\hline \multicolumn{4}{|c|}{ Çekirdeklenme modelleri } \\
\hline 15 & $\begin{array}{l}\text { Avrami-Erofeev } \\
(\mathrm{A} 1,5)\end{array}$ & {$[-\ln (1-\alpha)]^{2 / 3}$} & [39] \\
\hline 16 & Avrami-Erofeev (A2) & {$[-\ln (1-\alpha)]^{1 / 2}$} & [37] \\
\hline 17 & Avrami-Erofeev (A3) & {$[-\ln (1-\alpha)]^{1 / 3}$} & [37] \\
\hline 18 & Avrami-Erofeev (A4) & {$[-\ln (1-\alpha)]^{1 / 4}$} & [37] \\
\hline 19 & Prout-Tompkins (B1) & $\ln [\alpha /(1-\alpha)]$ & [39] \\
\hline 20 & Üs kanunu (P2/3) & $\alpha^{3 / 2}$ & [37] \\
\hline 21 & Üs kanunu (P2) & $\alpha^{1 / 2}$ & [37] \\
\hline 22 & Üs kanunu (P3) & $\alpha^{1 / 3}$ & [37] \\
\hline 23 & Üs kanunu (P4) & $\alpha^{1 / 4}$ & [40] \\
\hline 24 & $\begin{array}{l}\text { Eksponent üssü - } 1 . \\
\text { dereceden (E1) }\end{array}$ & $\ln \alpha$ & [39] \\
\hline 25 & $\begin{array}{l}\text { Eksponent üssü - } 2 . \\
\text { dereceden (E2) }\end{array}$ & $\ln \left(\alpha^{2}\right)$ & [39] \\
\hline \multicolumn{4}{|c|}{ Etkileşim geometrisi modelleri } \\
\hline 26 & $\begin{array}{l}\text { Silindirik sistemde } \\
\text { (R2) }\end{array}$ & $1-(1-\alpha)^{1 / 2}$ & [37] \\
\hline 27 & Küresel sistemde (R3) & $1-(1-\alpha)^{1 / 3}$ & [37] \\
\hline
\end{tabular}

\section{Bulgular ve tartışma}

\subsection{Kisa, elementel ve isll değer analizlerinin değerlendirilmesi}

Tablo 1'de verilen analiz sonuçları incelendiğinde kavun çekirdeğinin kısa analiz sonuçlarının tablodaki diğer biyokütle maddelerin yaklaşık olarak ortalama değerlerinde olduğu görülebilir. Ancak, diğer taraftan, elementel analiz sonuçları karşılaştırıldığında kavun çekirdeğinin belirgin bir biçimde, en yüksek $\mathrm{C}, \mathrm{N}$ ve $\mathrm{S}$ yüzdelerine, hurma çekirdeğinden sonra en yüksek ikinci $\mathrm{H}$ yüzdesine ve en düşük oksijen yüzdesine sahip olduğu görülebilir. $\mathrm{C}, \mathrm{H}$ içeriğinin yüksek $\mathrm{O}$ içeriğinin ise düşük olması, gerek kavun çekirdeğinin kendisinin, gerekse kendinden piroliz ile üretilecek potansiyel sıvı yakıtların ısıl değerinin yüksek olmasına olanak tanıdığından avantaj olarak değerlendirilebilir. Üst 1 sıl değerinin diğer biyokütlelere kıyasla belirgin bir biçimde yüksek olması bu açıklamanın ilk kısmını doğrular niteliktedir. $\mathrm{N}$ ve $\mathrm{S}$ içeriğinin yüksek olması ise, gerek kavun çekirdeğinin, gerekse ondan elde edilecek yakıtların yakılmasıyla salınacak $\mathrm{NO}_{x}$ ve $\mathrm{SO}_{x}$ miktarını arttıracağından bir dezavantaj olarak göze çarpmaktadır.

\subsection{Termogravimetrik ĕgrilerin incelenmesi}

Termogravimetrik analiz, kullanılan biyokütle numunesinin 1sıl bozunma özelliklerini ortaya çıkaran termogravimetri (TG) ve türevsel termogravimetri (DTG) eğrilerinden oluşur. TG eğrileri, sıcaklığa bağlı olarak bir numunenin kütle kaybını gösterirken, DTG eğrileri kütle kaybı hızını gösterir. Şekil 1'de 150-250 $\mu \mathrm{m}$ parçacık boyutlarındaki kavun çekirdeğinin $200 \mathrm{~mL} / \mathrm{dk}$ debide akan azot gazı atmosferinde çevre sicaklığından $800^{\circ} \mathrm{C}$ 'ye dört farklı isitma hizinda $\left(5,10,20\right.$ ve $\left.40^{\circ} \mathrm{C} / \mathrm{dk}\right)$ elde edilen $\mathrm{TG}$ ve DTG eğrileri verilmiştir.
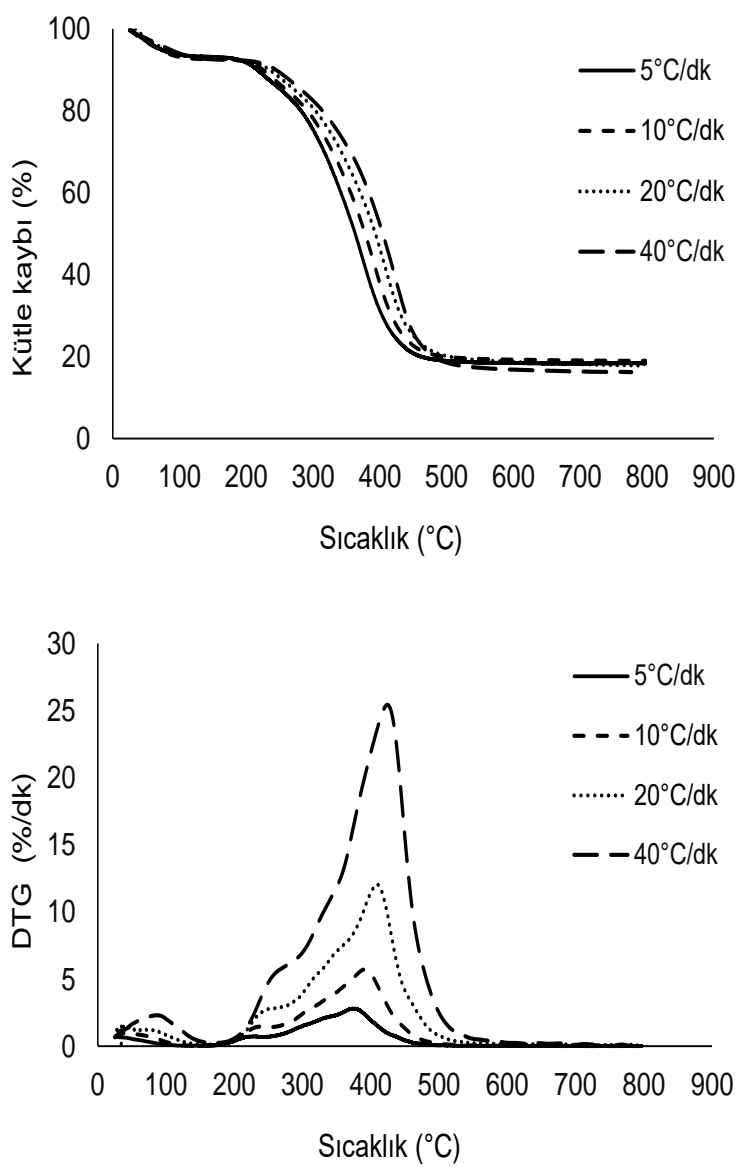

Şekil 1. Kavun çekirdeğinin TG ve DTG eğrileri

Şekil 1, 150-250 $\mu \mathrm{m}$ parçacık büyüklüğündeki kavun çekirdeği numunelerinin farklı 1sıtma hızlarındaki 1sıl bozunma eğrilerinin, ikisi aktif olmak üzere dört farklı piroliz basamağından oluştuğunu göstermektedir. Aktif piroliz basamakları, DTG eğrilerinde görülen piklerle temsil edilen en yüksek kütle kaybı hızlarının gözlendiği basamaklardır. $\mathrm{Bu}$ basamakların 1sil bozunma davranışlarının (karakteristiklerinin) belirlenmesi, bu basamaklara ait kinetik hesaplamaların yapılabilmesine olanak sağlamaktadır.

Şekil 1'de verilen eğrilerden $10^{\circ} \mathrm{C} / \mathrm{dk}$ 1sıtma hızı için elde edilen eğriler incelendiğinde, kavun çekirdeği piroliz prosesi ilk basamağının $25-196^{\circ} \mathrm{C}$ sıcaklık aralığında \%7.9 kütle 
kaybiyla gerçekleştiği tespit edilmiştir. TG eğrisinde ilk basamakta gerçekleşen bu kütle kaybı, nemin ve ayrıca bazı düşük molekül ağırlığına sahip uçucuların uzaklaştırıldığını göstermektedir. Kavun çekirdeği piroliz prosesi ikinci basamağı, $\quad 196-258^{\circ} \mathrm{C}$ sicaklık aralığında $\% 6.7$ kütle kaybıyla gerçekleşmiştir. DTG eğrisinde ikinci basamağa ait pik $232^{\circ} \mathrm{C}$ sicaklıkta maksimum gösteren omuz tipi piktir. $\mathrm{Bu}$ sıcaklıkta gerçekleşen maksimum kütle kaybı hızı ise $1.4 \% / d k$ olarak ölçülmüştür. Üçüncü basamak, $279-460^{\circ} \mathrm{C}$ sıcaklık aralığında, \%60.6 kütle kaybı oranıla gerçekleşmiştir. DTG eğrisinde bu basamağa denk gelen pikin maksimum noktas $390^{\circ} \mathrm{C}$ sicaklıkta gözlenmiş olup bu sıcaklıkta gerçekleşen maksimum kütle kaybı hızı ise $5.7 \% / \mathrm{dk}$ olarak ölçülmüştür. İkinci ve üçüncü basamaklar, gözlenen yüksek kütle kaybı hızları nedeniyle aktif piroliz basamaklarıdır. Biyokütlenin üç temel organik bileşeni olan hemiselüloz, selüloz ve ligninin, sırasiyla 210-325, 310-400 ve $160-900^{\circ} \mathrm{C}$ sicaklık aralıklarında isıl olarak bozundukları bilinmektedir [24]. Bu durumda, ikinci basamakta meydana gelen kütle kaybı esasen hemiselülozun isıl bozunmasına bağlanabilir. Bu basamak selülozun bilinen isıl bozunma sıcaklık aralığını kapsamadığından, selülozun bu basamaktaki kütle kaybına belirgin bir katkı sağlamadığı söylenebilir. Selülozun ve hemiselülozun bilinen isl bozunma sicaklık aralıkları (sirasiyla, $310-400^{\circ} \mathrm{C}$ ve 210 $325^{\circ} \mathrm{C}$ ) ile üçüncü basamağın gerçekleştiği sıcaklık aralığı $\left(279-460^{\circ} \mathrm{C}\right)$ karşılaştırıldığında, üçüncü basamakta temel olarak selülozun, kısmen de hemiselülozun isıl bozunmasının gerçekleştiği; ikinci ve üçüncü basamaklardaki kütle kayıpları da göz önüne alındığında kavun çekirdeğinin çoğunluğu selüloz olmak üzere önemli oranda holoselüloz (hemiselüloz + selüloz) içerdiği sonucuna varılabilir. Kavun çekirdeğinin son (dördüncü) piroliz basamağ $460-800{ }^{\circ} \mathrm{C}$ sıcaklık aralığında $\% 2.7$ kütle kaybıyla gerçekleşmiştir. DTG eğrisine bakıldığında bu basamakta gerçekleşen kütle kaybı hızlarının oldukça düşük olduğu görülebilmektedir. Bu nedenle dördüncü basamak, aktif değil pasif piroliz basamağıdır. Biyokütle maddelerin diğer temel bileşeni olan ligninin isıl bozunması $160-900{ }^{\circ} \mathrm{C}$ sıcaklık aralığında gerçekleştiğinden ve bu basamak sadece ligninin 1sıl bozunma sıcaklık aralığı ile örtüştüğünden, dördüncü basamakta karşılaşılan kütle kaybının ligninin ısıl bozunmasından kaynaklandığı söylenebilir. Ayrıca, ligninin TG ve DTG eğrilerinde uzun bir kuyruk şeklinde bozunma karakteristiği sergilemesi de bu basamağın ligninin isıl bozunmasına dair olduğunu onaylar niteliktedir. Ancak, ligninin 1sıl bozunmasının sadece dördüncü basamakta gerçekleşmediğini, aslında ikinci ve üçüncü basamaklarda da bir miktar ligninin diğer temel bileşenler ile eşzamanlı olarak bozunduğunu, dolayısıyla, bu bölüm kapsamında piroliz prosesi basamaklarındaki kütle kayıplarının nedenlerine dair yapılan atamaların temel atamalar olduğunu gözden kaçırmamak gerekir. Dördüncü basamak sonunda, bir başka deyişle tüm piroliz prosesi sonunda, kalan kütle miktarı \%18.9 olarak belirlenmiştir.

Kinetik parametreleri hesaplayabilmek için gerekli olan aktif piroliz basamaklarına ait karakteristik özellikler çalışılan tüm isıtma hızlarında $\left(5,10,20\right.$, ve $\left.40^{\circ} \mathrm{C} / \mathrm{dk}\right)$ belirlenmiş ve elde edilen sonuçlar Tablo 3 'te verilmiştir.
Tablo 3. Kavun çekirdeği aktif piroliz basamaklarının farklı 1sıtma hızları için karakteristik özellikleri

\begin{tabular}{lccccccccc}
\hline Isitma hizı & \multicolumn{2}{c}{$5{ }^{\circ} \mathrm{C} / \mathrm{dk}$} & \multicolumn{2}{c}{$10^{\circ} \mathrm{C} / \mathrm{dk}$} & \multicolumn{2}{c}{$20^{\circ} \mathrm{C} / \mathrm{dk}$} & \multicolumn{2}{c}{$40^{\circ} \mathrm{C} / \mathrm{dk}$} \\
\hline Basamak & II. & III. & II. & III. & II. & III. & II. & III. \\
\hline$T_{\mathrm{i}}^{\mathrm{a}}\left[{ }^{\circ} \mathrm{C}\right]$ & 182 & 261 & 196 & 279 & 203 & 288 & 211 & 300 \\
$T_{\mathrm{f}}^{\mathrm{b}}\left[{ }^{\circ} \mathrm{C}\right]$ & 240 & 449 & 258 & 460 & 265 & 469 & 272 & 480 \\
$T_{\max }{ }^{\mathrm{c}}\left[{ }^{\circ} \mathrm{C}\right]$ & 225 & 375 & 232 & 390 & 240 & 408 & 249 & 423 \\
$W_{\max }\left[{ }^{\mathrm{d}}[\% / \mathrm{dk}]\right.$ & 0.7 & 2.8 & 1.4 & 5.7 & 2.5 & 12.0 & 4.6 & 25.4
\end{tabular}

a Başlangıç sıcaklığı; b Bitiş sıcaklığı, ${ }^{c}$ Maks. kütle kaybı hızının gerçekleştiği sıcaklık; d Maks. kütle kaybı hızı

Tablo 3 incelendiğinde, 1sıtma hızının isıl bozunma karakteristik özellikleri üzerindeki etkisi açıç̧a görülmektedir. Isıtma hızı arttıkça aktif piroliz basamaklarının $T_{\mathrm{i}}, T_{\mathrm{f}}$ ve $T_{\max }$ değerlerinin de artarak daha yüksek sıcaklıklara kaydığı görülmüştür. Bu durum antep fistığı kabuğu [24], ceviz kabuğu [23], vişne sap1, vişne posası [25], buğday samanı, findık kabuğu, talaş tozu, kimyasal işlem görmüş talaş tozu [42], kavak [43], mısır sapı, beyaz huş ağacı kıymıkları [44], Hint hurması çekirdeği, Japon sedir ağacı, jüt çubuğu [27] ve elma posası [26] gibi çok çeşitli biyokütle maddelerle yapılan çalışmalarda da gözlenmiş, bilinen bir durumdur. Biyokütle maddeler 1sı iletiminde zayıf olduklarından, düşük 1sıtma hızları, parçacık iç bölgesindeki ve yüzeyindeki sıcaklıkların yakın değerlerde olması nedeniyle, termokimyasal reaksiyonların tamamlanması için yeterli süre sağlamıştır. Böylece, biyokütle parçacığın iç bölgesi ve yüzeyi neredeyse eş zamanlı olarak ısıl bozunmaya uğramıştır. Ancak, yüksek ısıtma hızlarında bu durumun tam aksine, parçacığın iç bölgesindeki sıcaklıklar bozunma sıcaklıklarına erişememiş ve piroliz reaksiyonlarının gecikmesine neden olarak TG/DTG eğrilerinin daha yüksek sıcaklıklara kaymasına neden olmuştur [45]. Tablo 3, 1sıtma hızının artmasıyla aktif piroliz basamakları için $W_{\max }$ değerlerinin de arttığını göstermektedir. Isıtma hızının artmasıyla piroliz sistemine birim zamanda giren enerji miktarı arttığı için maksimum kütle kaybı hızları artış göstermiştir. 5, 10, 20 ve $40^{\circ} \mathrm{C} / \mathrm{dk}$ 1sıtma hızlarında tüm piroliz prosesi sonunda kalan kütle miktarları sırasıyla, \%18.4, \%18.9, \%17.8 ve \%16.3 olarak tespit edilmiştir. Bu sonuçlar, çalışılan en yüksek ssıtma hızında dahi, piroliz prosesinin tamamlanması için yeterli sürenin sağlanabildiğini göstermektedir. Ayrıca, $20^{\circ} \mathrm{C} / \mathrm{dk}$ ve üzerindeki ısıtma hızlarında proses sonunda kalan kütle miktarlarında gözlenen hafif düşüş, 1sıtma hızının artmasıyla birlikte piroliz prosesinin kısalması sonucu çar oluşumunu arttıran katran parçalanması ve repolimerizasyon gibi ikincil reaksiyonların hafif bir ölçüde engellenmiş olmasına bağlanabilir [46].

\subsection{Kinetik hesaplamalar}

Kavun çekirdeğinin izotermal olmayan koşullarda gerçekleştirilen termogravimetrik analizlerinde elde edilen veriler üzerinden yapilan kinetik hesaplamalarda, model içermeyen eş dönüşümlü FWO, KAS, Starink ve model bazlı Coats-Redfern yöntemleri kullanılmıştır. 


\subsubsection{Model içermeyen kinetik yöntemler}

\section{FWO yöntemi}

$E_{\text {a }}$ değeri, Denklem (8) kullanılarak, bir reaksiyon modeline gerek duymadan $1 / T-\ln \beta$ grafiğinin eğiminden $\left(-1.052 E_{\mathrm{a}} / R\right)$ hesaplanabilir. Her iki aktif piroliz basamağ için sabit dönüşüm değerlerinde $1 / T-\ln \beta$ grafikleri Tablo 3 'teki değerlerden faydalanarak çizilmiş (Şekil 2), çizilen grafiklere doğrusal regresyon eşitliği oturtulmuş ve bu regresyon eşitliklerinin eğimlerinden $E_{\mathrm{a}}$ değerleri hesaplanmıştır. Şekil 2'de verilen $1 / T-\ln \beta$ grafiklerindeki her bir dönüşüm değeri için elde edilen doğrusal regresyon eşitlikleri, bu eşitliklerin korelasyon katsayıları $\left(R^{2}\right)$ ve eğimlerden hesaplanan $E_{\mathrm{a}}$ değerleri Tablo 4 'te verilmiştir.
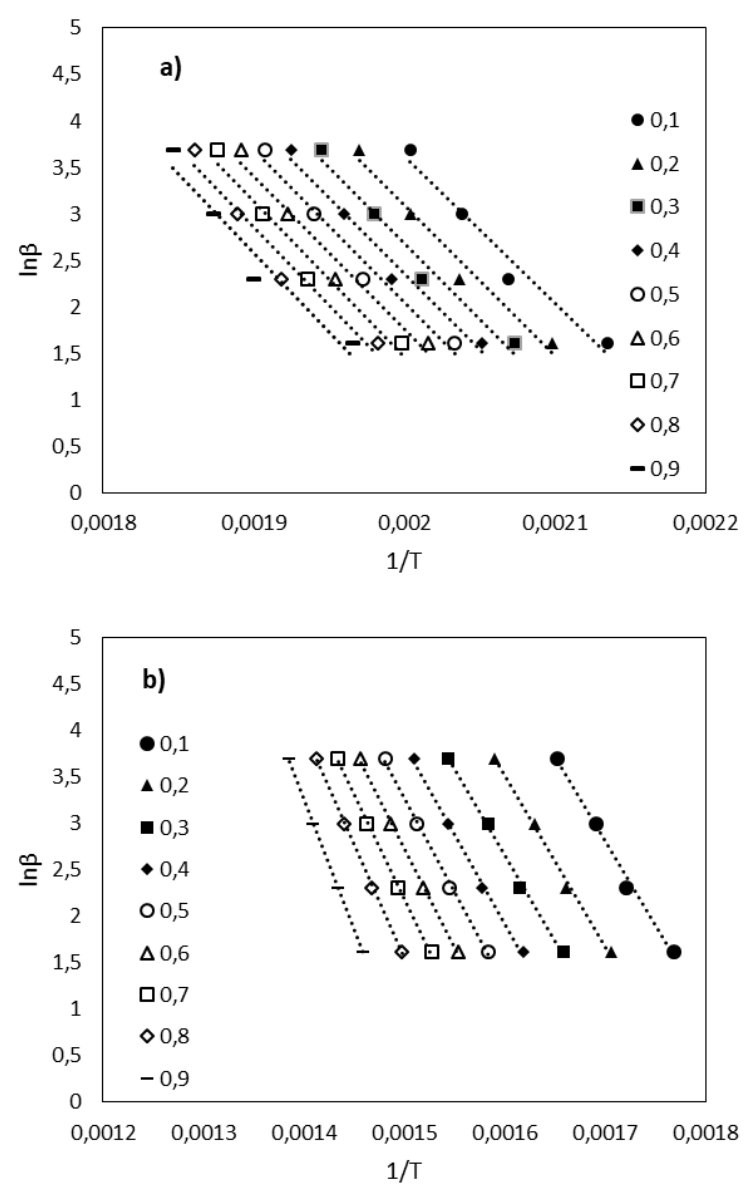

Şekil 2. FWO yöntemi için çizilen $1 / T-\ln \beta$ grafikleri a) ikinci basamak (b) üçüncü basamak

\section{KAS yöntemi}

$\mathrm{Bu}$ yöntemde $E_{\mathrm{a}}$ değeri, Denklem (9) baz alınarak bir reaksiyon modelinin bilinmesine gerek duyulmadan $1 / T-\ln$ $\left(\beta / T^{2}\right)$ grafiğinin eğiminden $\left(-E_{\mathrm{a}} / R\right)$ bulunabilir. Şekil 3, aktif piroliz basamakları için sabit dönüşüm değerlerinde çizilen $1 / T-\ln \left(\beta / T^{2}\right)$ grafiklerini göstermektedir. Bu grafiklerdeki her bir dönüşüm değeri için elde edilen doğrusal regresyon eşitlikleri, bu eşitliklerin $R^{2}$ değerleri ve eğimlerden hesaplanan $E_{\mathrm{a}}$ değerleri Tablo 5 'te verilmiştir.
Tablo 4. FWO yöntemi için elde edilen doğrusal regresyon eşitlikleri, bu eşitliklerin $R_{2}$ değerleri ve hesaplanan $E_{\text {a }}$ değerleri

\begin{tabular}{|c|c|c|c|c|}
\hline & $\alpha$ & $R^{2}$ & Regresyon eşitliği & $\begin{array}{c}E_{\mathrm{a}} \\
(\mathrm{kJ} / \mathrm{mol})\end{array}$ \\
\hline \multirow{9}{*}{ 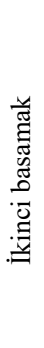 } & 0.1 & 0.9655 & $y=-15871 x+35.366$ & 125.4 \\
\hline & 0.2 & 0.9725 & $y=-16192 x+35.472$ & 128.0 \\
\hline & 0.3 & 0.9741 & $y=-16279 x+35.248$ & 128.7 \\
\hline & 0.4 & 0.9754 & $y=-16412 x+35.176$ & 129.7 \\
\hline & 0.5 & 0.9721 & $y=-16435 x+34.917$ & 129.9 \\
\hline & 0.6 & 0.9677 & $y=-16552 x+34.860$ & 130.8 \\
\hline & 0.7 & 0.9614 & $y=-16734 x+34.929$ & 132.2 \\
\hline & 0.8 & 0.9542 & $y=-16812 x+34.801$ & 132.9 \\
\hline & 0.9 & 0.9417 & $y=-17029 x+34.943$ & 134.6 \\
\hline \multirow{9}{*}{ 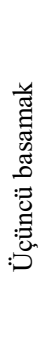 } & 0.1 & 0.9929 & $y=-18237 x+33.803$ & 144.1 \\
\hline & 0.2 & 0.9960 & $y=-18217 x+32.648$ & 144.0 \\
\hline & 0.3 & 0.9970 & $y=-18460 x+32.187$ & 145.9 \\
\hline & 0.4 & 0.9974 & $y=-19220 x+32.672$ & 151.9 \\
\hline & 0.5 & 0.9979 & $y=-20246 x+33.633$ & 160.0 \\
\hline & 0.6 & 0.9978 & $y=-21303 x+34.679$ & 168.4 \\
\hline & 0.7 & 0.9990 & $y=-22327 x+35.677$ & 176.5 \\
\hline & 0.8 & 0.9994 & $y=-24495 x+38.274$ & 193.6 \\
\hline & 0.9 & 0.9993 & $y=-28315 x+42.898$ & 223.8 \\
\hline
\end{tabular}
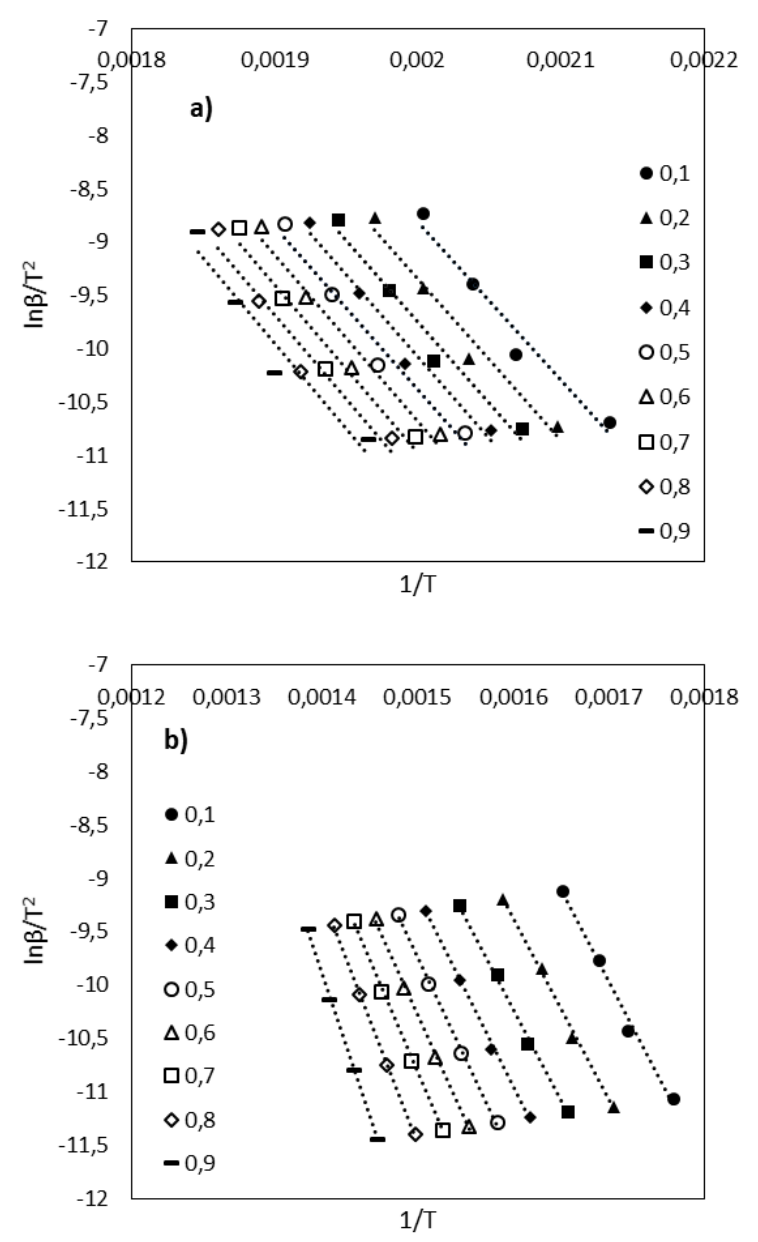

Şekil 3. KAS yöntemi için çizilen $1 / T-\ln \left(\beta / T^{2}\right)$ grafikleri a) ikinci basamak (b) üçüncü basamak 
Tablo 5. KAS yöntemi için elde edilen doğrusal regresyon eşitlikleri, bu eşitliklerin $R_{2}$ değerleri ve hesaplanan $E_{\mathrm{a}}$ değerleri

\begin{tabular}{|c|c|c|c|c|}
\hline & $\alpha$ & $R^{2}$ & Regresyon eşitliği & $\begin{array}{c}E_{\mathrm{a}} \\
(\mathrm{kJ} / \mathrm{mol}) \\
\end{array}$ \\
\hline \multirow{9}{*}{ 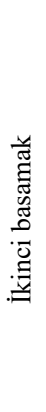 } & 0.1 & 0.9613 & $y=-14905 x+21.006$ & 123.9 \\
\hline & 0.2 & 0.9691 & $y=-15209 x+21.077$ & 126.4 \\
\hline & 0.3 & 0.9710 & $y=-15284 x+20.828$ & 127.1 \\
\hline & 0.4 & 0.9723 & $y=-15407 x+20.736$ & 128.1 \\
\hline & 0.5 & 0.9687 & $y=-15421 x+20.458$ & 128.2 \\
\hline & 0.6 & 0.9637 & $y=-15529 x+20.384$ & 129.1 \\
\hline & 0.7 & 0.9566 & $y=-15702 x+20.437$ & 130.5 \\
\hline & 0.8 & 0.9486 & $y=-15772 x+20.293$ & 131.1 \\
\hline & 0.9 & 0.9345 & $y=-15981 x+20.420$ & 132.9 \\
\hline \multirow{9}{*}{ 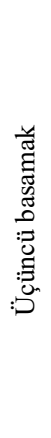 } & 0.1 & 0.9920 & $y=-17068 x+19.060$ & 141.9 \\
\hline & 0.2 & 0.9955 & $y=-17003 x+17.830$ & 141.4 \\
\hline & 0.3 & 0.9966 & $y=-17211 x+17.312$ & 143.1 \\
\hline & 0.4 & 0.9971 & $y=-17941 x+17.750$ & 149.2 \\
\hline & 0.5 & 0.9977 & $y=-18940 x+18.670$ & 157.5 \\
\hline & 0.6 & 0.9976 & $y=-19974 x+19.681$ & 166.1 \\
\hline & 0.7 & 0.9989 & $y=-20975 x+20.645$ & 174.4 \\
\hline & 0.8 & 0.9993 & $y=-23120 x+23.208$ & 192.2 \\
\hline & 0.9 & 0.9992 & $y=-26909 x+27.786$ & 223.7 \\
\hline
\end{tabular}

Starink yöntemi

Starink yönteminde $E_{\mathrm{a}}$ değerini hesaplamak için Denklem (9) göz önüne alındığında bir reaksiyon modelinin bilinmesine gerek duyulmadan $1 / T-\ln \left(\beta / T^{1,92}\right)$ grafiğinin eğiminin $\left(-1,0008 E_{\mathrm{a}} / R\right)$ bulunması yeterlidir. Aktif piroliz basamakları için sabit dönüșüm değerlerinde çizilen $1 / T-\ln$ $\left(\beta / T^{1,92}\right)$ grafikleri Şekil 4 'te verilmiştir. Bu grafiklerdeki her bir dönüşüm değeri için elde edilen doğrusal regresyon eşitlikleri, bu eşitliklerin $R^{2}$ değerleri ve eğimlerden hesaplanan $E_{\mathrm{a}}$ değerleri Tablo 6'da listelenmiştir.

İkinci basamak için FWO, KAS ve Starink yöntemleriyle hesaplanmış ortalama $E_{\text {a }}$ değerleri sırasıyla, 130.2 . 128.6 ve $128.8 \mathrm{~kJ} / \mathrm{mol}$ 'dür. Üçüncü basamak için aynı yöntemlerden elde edilen ortalama $E_{\mathrm{a}}$ değerleri ise sirasiyla, 167.6. 165.5 ve $165.8 \mathrm{~kJ} / \mathrm{mol}$ 'dür. Bu sonuçlar göz önüne alındığında, gerek ikinci gerekse üçüncü basamaklar için hesaplanan ortalama $E_{\text {a }}$ değerlerinin oldukça yakın değerler olması nedeniyle, model içermeyen yöntemlerin birbirleriyle uyumlu sonuçlar verdiği söylenebilir. Ayrıca, dikkat edilirse her üç yöntemde de, üçüncü basamak için hesaplanan ortalama $E_{\mathrm{a}}$ değerleri, ikinci basamak için hesaplanan ortalama $E_{\mathrm{a}}$ değerlerinden yüksektir. Bu durum, ikinci basamağın temel olarak hemiselülozun, üçüncü basamağın ise temel olarak selülozun 1sıl bozunmasını içermesinden ve selülozun ısıl kararlılığının hemiselüloza göre daha yüksek olduğunun bilinmesinden dolayı, selülozun 1sıl bozunma reaksiyonları için daha yüksek enerji gereksinimi olacağı mantığıyla olağan karşılanmıştır.
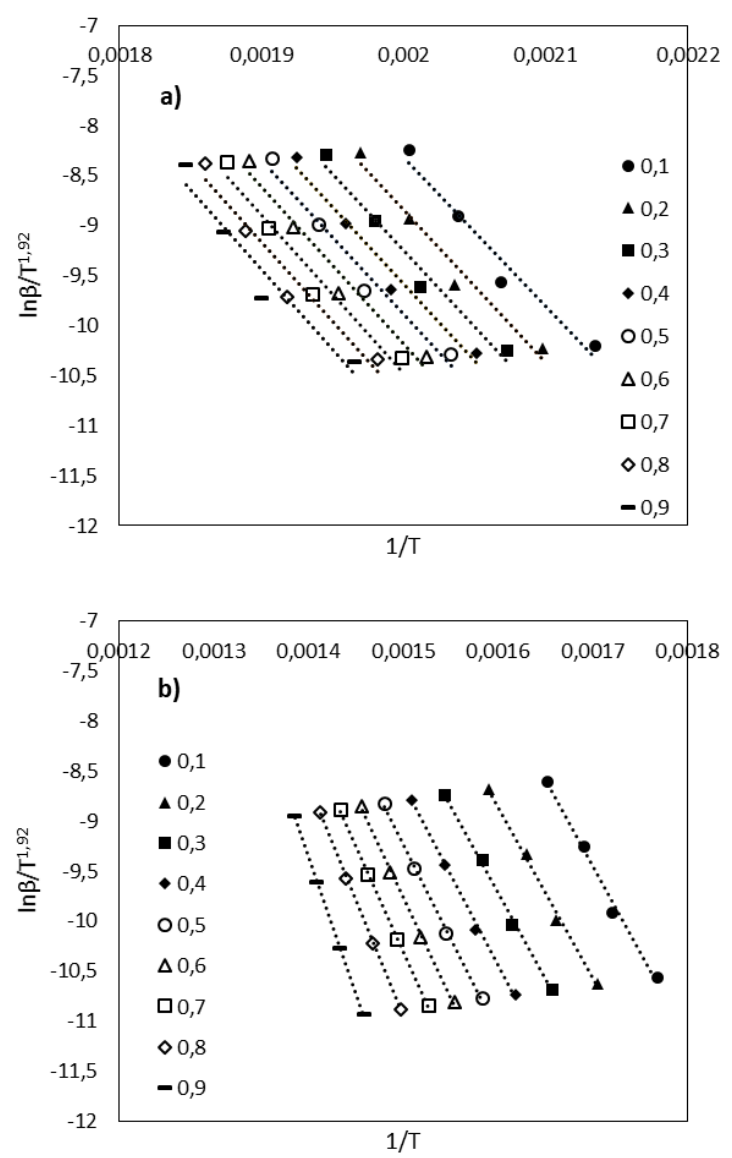

Şekil 4. Starink yöntemi için çizilen $1 / T-\ln \left(\beta / T^{1,92}\right)$ grafikleri a) ikinci basamak (b) üçüncü basamak

Tablo 6. Starink yöntemi için elde edilen doğrusal regresyon eşitlikleri, bu eşitliklerin $R_{2}$ değerleri ve hesaplanan $E_{\mathrm{a}}$ değerleri

\begin{tabular}{|c|c|c|c|c|}
\hline & $\alpha$ & $R^{2}$ & Regresyon eşitliği & $\begin{array}{c}E_{\mathrm{a}} \\
(\mathrm{kJ} / \mathrm{mol})\end{array}$ \\
\hline \multirow{9}{*}{ 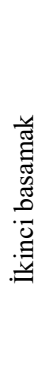 } & 0.1 & 0.9615 & $y=-14943 x+21.580$ & 124.1 \\
\hline & 0.2 & 0.9693 & $y=-15248 x+21.653$ & 126.7 \\
\hline & 0.3 & 0.9711 & $y=-15324 x+21.405$ & 127.3 \\
\hline & 0.4 & 0.9725 & $y=-15447 x+21.313$ & 128.3 \\
\hline & 0.5 & 0.9688 & $y=-15461 x+21.037$ & 128.4 \\
\hline & 0.6 & 0.9639 & $y=-15570 x+20.963$ & 129.3 \\
\hline & 0.7 & 0.9568 & $y=-15743 x+21.016$ & 130.8 \\
\hline & 0.8 & 0.9488 & $y=-15813 x+20.873$ & 131.4 \\
\hline & 0.9 & 0.9349 & $y=-16023 x+21.001$ & 133.1 \\
\hline \multirow{9}{*}{ 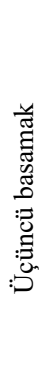 } & 0.1 & 0.9920 & $y=-17115 x+19.650$ & 142.2 \\
\hline & 0.2 & 0.9955 & $y=-17051 x+18.423$ & 141.6 \\
\hline & 0.3 & 0.9966 & $y=-17260 x+17.907$ & 143.4 \\
\hline & 0.4 & 0.9971 & $y=-17992 x+18.347$ & 149.5 \\
\hline & 0.5 & 0.9977 & $y=-18993 x+19.269$ & 157.8 \\
\hline & 0.6 & 0.9976 & $y=-20027 x+20.280$ & 166.4 \\
\hline & 0.7 & 0.9989 & $y=-21029 x+21.246$ & 174.7 \\
\hline & 0.8 & 0.9993 & $y=-23175 x+23.811$ & 192.5 \\
\hline & 0.9 & 0.9992 & $y=-26965 x+28.391$ & 224.0 \\
\hline
\end{tabular}


$\mathrm{Bu}$ çalışmanın sonuçları, $E_{\mathrm{a}}$ değerinin $\alpha$ değerine bağlı olarak değiştiğini göstermiştir (Şekil 5). Örneğin, ikinci basamak için $E_{\mathrm{a}}-\alpha$ ilişkisi incelendiğinde (Şekil 5a), FWO, KAS ve Starink yöntemlerinin tümünde, $\alpha$ değerinin artmasıyla $E_{\mathrm{a}}$ değerinin de hafif artışlar göstererek yaklaşık olarak 124-134 kJ/mol gibi nispeten dar bir aralıkta değiştiğ görülebilir. Üçüncü basamakta da, tüm model içermeyen kinetik yöntemlerde, $E_{\mathrm{a}}$ değeri $\alpha$ değerine bağl1 olarak değişmiştir (Şekil 5b). Ancak, bu kez değişim ikinci basamağın aksine çok daha geniş bir aralıkta (140-225 $\mathrm{kJ} / \mathrm{mol}$ değerleri arasında) ve değişken eğimlere sahip üç farklı bölgede olacak şekilde gerçekleşmiştir. Üçüncü basamakta, $0,1 \leq \alpha<0.3$ için $E_{\mathrm{a}}$ değeri hemen hemen 140-145 $\mathrm{kJ} / \mathrm{mol}$ değer aralığında neredeyse sabit seyretmiştir. $0.3 \leq \alpha \leq 0.7$ aralığında, $\alpha$ 'nın artmasıyla $E_{\mathrm{a}}$ değeri de artarak $145-175 \mathrm{~kJ} / \mathrm{mol}$ aralığında değerler almıştır. $0.7<\alpha \leq 0.9$ aralığında ise, $E_{\text {a }}$ değeri $\alpha$ değerinin artmasıyla çok daha keskin artışlar göstermiş ve 175-225 kJ/mol arasında değişmiştir. Üçüncü basamakta tüm model içermeyen yöntemlerde $\alpha=0.9$ değerinde gözlenen yüksek $E_{\mathrm{a}}$ değerleri, çar ara ürünlerinin stabilize edilmesi için yüksek enerji ihtiyacının varlığını işaret etmektedir [47].

Şekil 5'te dikkat çeken bir diğer durum, ikinci basamaktaki FWO sonuçları hariç, tüm yöntemlerle elde edilen $E_{\mathrm{a}}-\alpha$ ilişkisi grafiklerinin üst üste çakışmasıdır. $\mathrm{Bu}$ durum, model içermeyen yöntemlerde edilen sonuçların birbirleriyle son derece uyumlu olduğunu göstermektedir. FWO, KAS ve Starink yöntemleri aynı genel forma sahip yöntemlerdir. $\mathrm{Bu}$ genel form, $\ln \left(\beta / T^{\mathrm{B}}=\mathrm{Sabit}-\mathrm{C}(E /(R T))\right.$ eşitliği şeklindedir ve belirtilen üç yöntem için $B$ ve $C$ katsayıları değişmektedir [48]. Bu nedenle, bu yöntemlerden benzer sonuçların elde edilmesi beklenen bir sonuçtur.
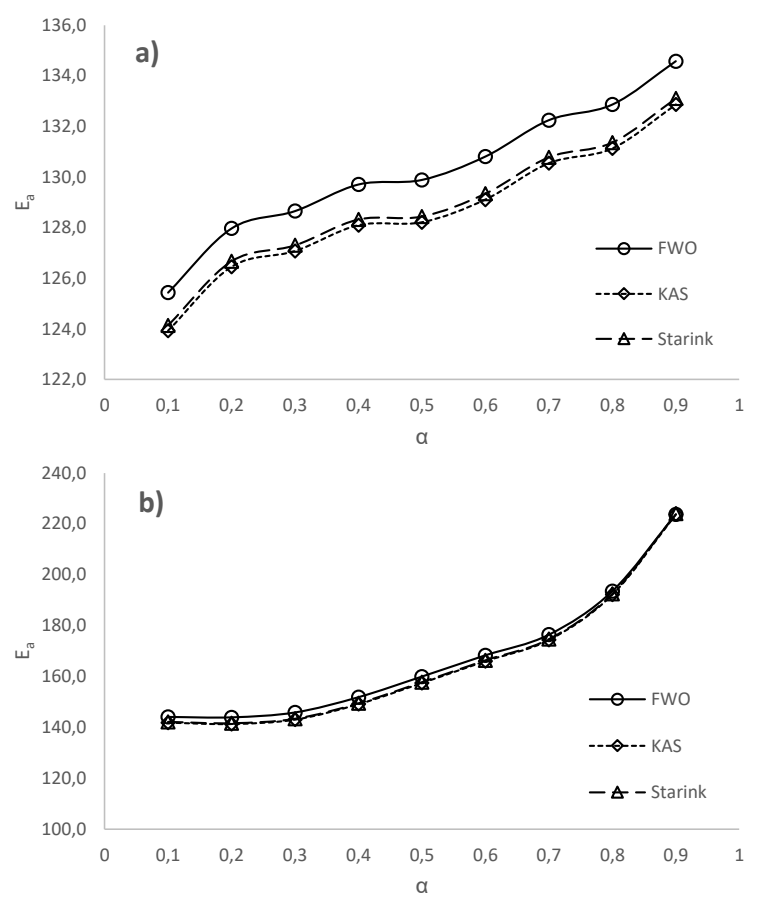

Şekil 5. FWO, KAS ve Starink yöntemleri için $E_{\mathrm{a}}-\alpha$ ilişkisi a) ikinci basamak (b) üçüncü basamak

\subsubsection{Model bazlı kinetik yöntem}

Coats-Redfern yöntemi

Denklem (11)'e göre $E_{\mathrm{a}}$ ve $A$ değerleri $1 / T$ 'ye karşıllk çizilen $\ln \left(\frac{g(\alpha)}{T^{2}}\right)$ grafiklerinde elde edilen doğrunun sırasıyla, eğiminden ve kayımından hesaplanabilir. Hesaplanacak değerler $g(\alpha)$ 'ya, yani, reaksiyon mekanizmasının seçimine bağlıdır. Bu nedenle, Tablo 2'deki 27 farklı reaksiyon mekanizmasına ait $g(\alpha)$ değerleri kullanılarak aktif piroliz basamakları için, çalışılan ısıtma hızlarında $1 / T-\ln \left(\frac{g(\alpha)}{T^{2}}\right)$ grafikleri çizilmiştir. $\mathrm{Bu}$ grafiklere doğrusal regresyon eşitlikleri oturtulmuş ve bu eşitliklerin $R^{2}$ değerleri hesaplanmıştır. $1 / T-\ln \left(\frac{g(\alpha)}{T^{2}}\right)$ grafiklerinin doğru çıkması gerektiğinden denenen reaksiyon mekanizmalarından en yüksek $R^{2}$ değerini sağlayanının belirlenmesi yöntemi izlenmiştir. Farklı reaksiyon mekanizmaları ile elde edilen $1 / T-\ln \left(\frac{g(\alpha)}{T^{2}}\right)$ grafiklerine oturtulan doğrusal regresyon eşitliklerinin $R^{2}$ değerleri ve bu eşitliklerin eğimlerinden hesaplanan $E_{\mathrm{a}}$ değerleri sırasıyla Tablo 7 ve 8 'de verilmiştir. Tablo 2'de verilen reaksiyon mekanizmalarına ek olarak, en yüksek $R^{2}$ değerine sahip reaksiyon derecesi $(n)$ değerinin, bir başka deyişle, kimyasal reaksiyon modelleri arasında en yüksek $R^{2}$ değerini veren $n$ değerinin tam olarak bulunması amaciyla, Tablo 2'de verilen kimyasal reaksiyon modelleri arasında en yüksek $R^{2}$ değerine sahip $n$ değerine yakın çeşitli $n$ değerleri seçilerek $R^{2}-n$ grafikleri oluşturulmuştur (Şekil 6). Bu grafiklere Şekil 6'daki yüksek $R^{2}$ değerlerinden de görüldüğü gibi güvenilir olarak ikinci dereceden polinom eşitlikleri oturtulmuştur. En yüksek $R^{2}$ değerine sahip $n$ değeri ikinci dereceden polinomun tepe noktası olduğundan, polinom eşitliğinin diferansiyeli alınıp sıfıra eşitlenerek bu değer bulunmuş ve Tablo 2'de verilen reaksiyon mekanizmalarına ek olarak Tablo 7 ve 8 'e eklenmiştir.

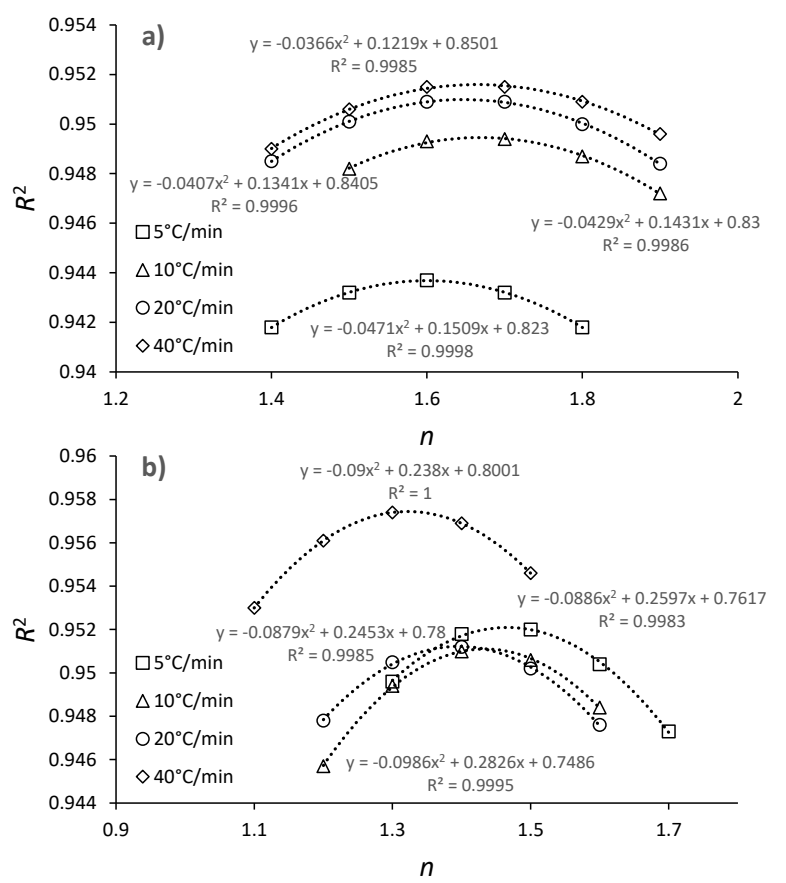

Şekil 6. Coats-Redfern yöntemi için oluşturulan $R^{2}-n$ grafikleri a) ikinci basamak (b) üçüncü basamak 
Tablo 7. Coats-Redfern yöntemi ile kavun çekirdeği aktif piroliz basamakları için çalışılan ısıtma hızlarında ve denenen reaksiyon mekanizmalarında oturtulan regresyon eşitliklerinin $R^{2}$ değerleri

\begin{tabular}{|c|c|c|c|c|c|c|c|c|c|}
\hline \multirow{3}{*}{ No } & \multirow{3}{*}{$\begin{array}{l}\text { Reaksiyon } \\
\text { Mekanizması }\end{array}$} & \multicolumn{8}{|c|}{$R^{2}$} \\
\hline & & \multicolumn{2}{|c|}{$5^{\circ} \mathrm{C} / \mathrm{dk}$} & \multicolumn{2}{|c|}{$10^{\circ} \mathrm{C} / \mathrm{dk}$} & \multicolumn{2}{|c|}{$20^{\circ} \mathrm{C} / \mathrm{dk}$} & \multicolumn{2}{|c|}{$40^{\circ} \mathrm{C} / \mathrm{dk}$} \\
\hline & & II. $^{\mathrm{a}}$ & III. $^{b}$ & II. & III. & II. & III. & II. & III. \\
\hline 1 & F0 & 0.8483 & 0.7918 & 0.8464 & 0.7948 & 0.8581 & 0.8149 & 0.8651 & 0.8402 \\
\hline 2 & F0.5 & 0.8910 & 0.8671 & 0.8909 & 0.8701 & 0.8992 & 0.8834 & 0.9035 & 0.9024 \\
\hline 3 & F1.0 & 0.9264 & 0.9304 & 0.9282 & 0.9318 & 0.9332 & 0.9365 & 0.9348 & 0.9472 \\
\hline 4 & F1.322 & - & - & - & - & - & - & - & 0.9574 \\
\hline 5 & F1.395 & - & - & - & - & - & 0.9512 & - & - \\
\hline 6 & F1.433 & - & - & - & 0.9510 & - & - & - & - \\
\hline 7 & F1.466 & - & 0.9521 & - & - & - & - & - & - \\
\hline 8 & F1.5 & 0.9432 & 0.9520 & 0.9482 & 0.9506 & 0.9501 & 0.9502 & 0.9506 & 0.9546 \\
\hline 9 & F1.602 & 0.9437 & - & - & - & - & - & - & - \\
\hline 10 & F1.647 & - & - & - & - & 0.9510 & - & - & - \\
\hline 11 & F1.665 & - & - & - & - & - & - & 0.9516 & - \\
\hline 12 & F1.668 & - & - & 0.9495 & - & - & - & - & - \\
\hline 13 & $\mathrm{~F} 2$ & 0.9369 & 0.9316 & 0.9450 & 0.9274 & 0.9462 & 0.9258 & 0.9477 & 0.9258 \\
\hline 14 & $\mathrm{~F} 2.5$ & 0.9156 & 0.8970 & 0.9263 & 0.8912 & 0.9278 & 0.8890 & 0.9311 & 0.8864 \\
\hline 15 & F3 & 0.8889 & 0.8641 & 0.9017 & 0.8578 & 0.9036 & 0.8546 & 0.9084 & 0.8504 \\
\hline 16 & F3.5 & 0.8626 & 0.8372 & 0.8770 & 0.8308 & 0.8790 & 0.8263 & 0.8847 & 0.8212 \\
\hline 17 & $\mathrm{~F} 4$ & 0.8389 & 0.8159 & 0.8545 & 0.8097 & 0.8564 & 0.8041 & 0.8625 & 0.7982 \\
\hline 18 & D1 & 0.8559 & 0.8201 & 0.8543 & 0.8215 & 0.8655 & 0.8391 & 0.8719 & 0.8609 \\
\hline 19 & D2 & 0.8810 & 0.8586 & 0.8802 & 0.8603 & 0.8898 & 0.8748 & 0.8948 & 0.8935 \\
\hline 20 & D3 & 0.9087 & 0.9045 & 0.9094 & 0.9062 & 0.9166 & 0.9155 & 0.9203 & 0.9300 \\
\hline 21 & D4 & 0.8909 & 0.8751 & 0.8907 & 0.8769 & 0.8992 & 0.8896 & 0.9035 & 0.9070 \\
\hline 22 & D5 & 0.9427 & 0.9554 & 0.9466 & 0.9548 & 0.9491 & 0.9555 & 0.9496 & 0.9612 \\
\hline 23 & A1.5 & 0.9230 & 0.9209 & 0.9248 & 0.9231 & 0.9300 & 0.9284 & 0.9317 & 0.9407 \\
\hline 24 & $\mathrm{~A} 2$ & 0.9194 & 0.9096 & 0.9211 & 0.9128 & 0.9265 & 0.9189 & 0.9284 & 0.9331 \\
\hline 25 & A3 & 0.9114 & 0.8792 & 0.9130 & 0.8857 & 0.9188 & 0.8936 & 0.9212 & 0.9131 \\
\hline 26 & A4 & 0.9021 & 0.8329 & 0.9036 & 0.8453 & 0.9099 & 0.8561 & 0.9128 & 0.8835 \\
\hline 27 & $\mathrm{~B} 1^{\mathrm{c}}$ & 0.6383 & 0.6765 & 0.6522 & 0.6750 & 0.6399 & 0.6675 & 0.6269 & 0.6642 \\
\hline 28 & $\mathrm{P} 2 / 3$ & 0.8534 & 0.8113 & 0.8517 & 0.8132 & 0.8631 & 0.8316 & 0.8697 & 0.8544 \\
\hline 29 & $\mathrm{P} 2$ & 0.8315 & 0.7157 & 0.8287 & 0.7237 & 0.8416 & 0.7503 & 0.8498 & 0.7849 \\
\hline 30 & P3 & 0.8119 & 0.6025 & 0.8082 & 0.6193 & 0.8223 & 0.6542 & 0.8320 & 0.7020 \\
\hline 31 & $\mathrm{P} 4$ & 0.7892 & 0.4382 & 0.7842 & 0.4687 & 0.7997 & 0.5122 & 0.8113 & 0.5767 \\
\hline 32 & $\mathrm{E} 1^{\mathrm{d}}$ & N/A & N/A & N/A & N/A & N/A & N/A & N/A & N/A \\
\hline 33 & $E 2^{d}$ & N/A & N/A & N/A & N/A & N/A & N/A & N/A & N/A \\
\hline 34 & $\mathrm{R} 2$ & 0.8910 & 0.8671 & 0.8909 & 0.8701 & 0.8992 & 0.8834 & 0.9035 & 0.9024 \\
\hline 35 & R3 & 0.9043 & 0.8910 & 0.9048 & 0.8936 & 0.9124 & 0.9041 & 0.9164 & 0.9208 \\
\hline
\end{tabular}

İkinci basamak; ' Üçüncü basamak; ' B1 sonuçları $\alpha<0.5$ için "tanımsız" olan $\ln \left(g(\alpha) / T^{2}\right)$ değerlerinden etkilenmiştir;

${ }^{\mathrm{d}} \mathrm{E} 1$, E2 yöntemleri $0.1 \leq \alpha \leq 0.9$ için $\ln \left(g(\alpha) / T^{2}\right)$ değerleri "tanımsız" olduğundan uygulanamamıştır.

Tablo 7'den görülebileceği üzere aktif piroliz basamaklarında genel olarak en yüksek $R^{2}$ değerleri belirgin bir biçimde F1.5 civarında ve D5 mekanizmalarında elde edilmiştir. İkinci basamak için en yüksek $R^{2}$ değeri, çalışılan tüm isıtma hızlarında $\sim \mathrm{F} 1.5$ civarında elde edilmiştir. $R^{2}-n$ grafiklerinden (Şekil 6a), ikinci basamak için en yüksek $R^{2}$ değerlerinin gözlendiği tam reaksiyon dereceleri 5, 10, 20 ve $40^{\circ} \mathrm{C} / \mathrm{dk}$ isitma hizlarında sirasiyla, $1.602,1.668,1.647$ ve 1.665 olarak bulunmuştur. Bu değerlerin ortalaması alınarak, ikinci bölgedeki reaksiyon derecesinin ortalama olarak 1.65 ve reaksiyon mekanizmasının F1.65 olduğu tespit edilmiştir. Üçüncü basamak için yine $R^{2}-n$ grafiklerinden (Şekil 6b) en yüksek $R^{2}$ değerlerinin gözlendiği tam reaksiyon dereceleri hesaplanmış $\left(5,10,20\right.$ ve $40^{\circ} \mathrm{C} / \mathrm{dk}$ isıtma hızlarında sırasıyla $1.466,1.433,1.395$ ve 1.322 ) ancak, D5 reaksiyon mekanizması için hesaplanan $R^{2}$ değerlerinin çalışılan tüm ısıtma hızlarında bu değerlerden de yüksek olduğu belirlenmiştir. $\mathrm{Bu}$ nedenle, üçüncü basamağın reaksiyon mekanizması çalışılan tüm 1sıttma hızlarında denenen reaksiyon mekanizmaları arasında en yüksek $R^{2}$ değerine sahip olan D5 difüzyon modelidir. Dikkat edilirse, gerek ikinci gerekse üçüncü basamakta reaksiyon mekanizması çalışılan tüm ısıtma hızlarında aynıdır. Bundan dolayı, reaksiyon mekanizmasının çalışılan isıtma hızından bağımsız olduğu sonucuna ulaşılabilir.

$E_{\text {a }}$ değerlerinin tüm çalıșılan ısıtma hızlarında reaksiyon mekanizmasına bağlı değişimi, yani, $E_{\mathrm{a}}{ }^{\prime}$ nın seçilen reaksiyon mekanizmasının kuvvetli bir fonksiyonu olduğu açıça görülmektedir (Tablo 8). İkinci basamakta 5, 10, 20 ve $40^{\circ} \mathrm{C} /$ dk'daki F1.602, F1.668, F1.647 ve F1.665 reaksiyon mekanizmaları için $E_{\text {a }}$ değerleri sırasıyla, 201.8, 208.0, 207.0 ve $215.5 \mathrm{~kJ} / \mathrm{mol}$ (Tablo 8) olarak hesaplanmıştır. 
Tablo 8. Coats-Redfern yöntemi ile kavun çekirdeği aktif piroliz basamakları için çalışılan ısıtma hızlarında ve denenen reaksiyon mekanizmalarında oturtulan regresyon eşitliklerinin eğimlerinden hesaplanan $E_{\mathrm{a}}$ değerleri

\begin{tabular}{|c|c|c|c|c|c|c|c|c|c|}
\hline \multirow{3}{*}{ No } & \multirow{3}{*}{$\begin{array}{l}\text { Reaksiyon } \\
\text { Mekanizması }\end{array}$} & \multicolumn{8}{|c|}{$E_{\mathrm{a}}(\mathrm{kJ} / \mathrm{mol})$} \\
\hline & & \multicolumn{2}{|c|}{$5^{\circ} \mathrm{C} / \mathrm{dk}$} & \multicolumn{2}{|c|}{$10^{\circ} \mathrm{C} / \mathrm{dk}$} & \multicolumn{2}{|c|}{$20^{\circ} \mathrm{C} / \mathrm{dk}$} & \multicolumn{2}{|c|}{$40^{\circ} \mathrm{C} / \mathrm{dk}$} \\
\hline & & II. $^{\mathrm{a}}$ & III. $^{\text {b }}$ & II. & III. & II. & III. & II. & III. \\
\hline 1 & F0 & 135.6 & 58.2 & 136.1 & 62.4 & 138.1 & 64.8 & 145.4 & 69.0 \\
\hline 2 & F0.5 & 151.5 & 68.8 & 152.3 & 74.0 & 154.4 & 76.3 & 162.2 & 81.0 \\
\hline 3 & F1.0 & 171.5 & 83.7 & 173.3 & 90.4 & 174.4 & 92.2 & 182.2 & 97.8 \\
\hline 4 & F1.322 & - & - & - & - & - & - & - & 111.1 \\
\hline 5 & F1.395 & - & - & - & - & - & 108.4 & - & - \\
\hline 6 & F1.433 & - & - & - & 109.2 & - & - & - & - \\
\hline 7 & F1.466 & - & 102.3 & - & - & - & - & - & - \\
\hline 8 & F1.5 & 196.2 & 103.8 & 198.4 & 112.5 & 198.9 & 113.2 & 206.6 & 119.6 \\
\hline 9 & F1.602 & 201.8 & - & - & - & - & - & - & - \\
\hline 10 & F1.647 & - & - & - & - & 207.0 & - & - & - \\
\hline 11 & F1.665 & - & - & - & - & - & - & 215.5 & - \\
\hline 12 & F1.668 & - & - & 208.0 & - & - & - & - & - \\
\hline 13 & $\mathrm{~F} 2$ & 225.1 & 128.2 & 228.2 & 139.4 & 227.5 & 138.7 & 234.7 & 146.1 \\
\hline 14 & $\mathrm{~F} 2.5$ & 257.3 & 155.5 & 261.3 & 169.5 & 259.3 & 167.2 & 266.0 & 175.8 \\
\hline 15 & F3 & 291.7 & 184.5 & 296.8 & 201.5 & 293.4 & 197.6 & 299.6 & 207.6 \\
\hline 16 & F3.5 & 327.9 & 214.8 & 334.2 & 234.9 & 329.2 & 229.4 & 334.9 & 240.6 \\
\hline 17 & $\mathrm{~F} 4$ & 365.3 & 246.0 & 372.8 & 269.3 & 366.3 & 262.0 & 371.5 & 274.7 \\
\hline 18 & D1 & 279.3 & 126.8 & 280.4 & 135.4 & 284.6 & 140.4 & 299.3 & 148.9 \\
\hline 19 & $\mathrm{D} 2$ & 298.4 & 139.0 & 300.0 & 148.7 & 304.5 & 153.6 & 320.2 & 162.8 \\
\hline 20 & D3 & 323.3 & 156.8 & 325.7 & 168.3 & 329.5 & 172.7 & 345.5 & 182.8 \\
\hline 21 & D4 & 306.5 & 144.7 & 308.3 & 155.0 & 312.7 & 159.7 & 328.5 & 169.2 \\
\hline 22 & D5 & 383.0 & 203.5 & 387.1 & 219.6 & 389.0 & 222.0 & 404.5 & 234.2 \\
\hline 23 & A 1.5 & 111.7 & 52.4 & 112.8 & 56.8 & 113.5 & 57.9 & 118.7 & 61.6 \\
\hline 24 & $\mathrm{~A} 2$ & 81.7 & 36.7 & 82.5 & 39.9 & 83.0 & 40.8 & 86.9 & 43.5 \\
\hline 25 & A3 & 51.8 & 21.0 & 52.2 & 23.1 & 52.5 & 23.6 & 55.1 & 25.3 \\
\hline 26 & $\mathrm{~A} 4$ & 36.9 & 13.2 & 37.1 & 14.7 & 37.3 & 15.0 & 39.2 & 16.3 \\
\hline 27 & $\mathrm{~B} 1^{\mathrm{c}}$ & -565.3 & -313.3 & -580.0 & -341.7 & -587.0 & -350.4 & -604.0 & -364.2 \\
\hline 28 & $\mathrm{P} 2 / 3$ & 207.4 & 92.5 & 208.2 & 98.9 & 211.3 & 102.6 & 222.4 & 109.0 \\
\hline 29 & $\mathrm{P} 2$ & 63.8 & 24.0 & 63.9 & 25.9 & 64.8 & 27.0 & 68.4 & 29.0 \\
\hline 30 & P3 & 39.9 & 12.5 & 39.8 & 13.8 & 40.4 & 14.5 & 42.7 & 15.7 \\
\hline 31 & $\mathrm{P} 4$ & 27.9 & 6.8 & 27.8 & 7.7 & 28.1 & 8.2 & 29.9 & 9.1 \\
\hline 32 & $\mathrm{E} 1^{\mathrm{d}}$ & N/A & N/A & N/A & N/A & N/A & N/A & N/A & N/A \\
\hline 33 & $\mathrm{E} 2^{\mathrm{d}}$ & N/A & N/A & N/A & N/A & N/A & N/A & N/A & N/A \\
\hline 34 & $\mathrm{R} 2$ & 151.5 & 68.8 & 152.3 & 74.0 & 154.4 & 76.3 & 162.2 & 81.0 \\
\hline 35 & R3 & 157.6 & 73.3 & 158.7 & 78.8 & 160.6 & 81.0 & 168.5 & 85.9 \\
\hline
\end{tabular}

a İkinci basamak; ${ }^{b}$ Üçüncü basamak; ${ }^{c}$ B1 sonuçları $\alpha<0.5$ için "tanımsız" olan $\ln \left(g(\alpha) / T^{2}\right)$ değerlerinden etkilenmiştir;

${ }^{\mathrm{d}} \mathrm{E} 1$, E2 yöntemleri $0.1 \leq \alpha \leq 0.9$ için $\ln \left(g(\alpha) / T^{2}\right)$ değerleri "tanımsız" olduğundan uygulanamamıştır.

$\mathrm{Bu}$ değerlerin ortalaması olarak $\mathrm{F} 1.65$ reaksiyon mekanizması için ortalama $E_{\mathrm{a}}$ değeri $208.1 \mathrm{~kJ} / \mathrm{mol}$ olarak belirlenmiștir. Bu basamaktaki F1.602, F1.668, F1.647 ve F1.665 reaksiyon mekanizmaları için hesaplanan $A$ değerleri ise sirasiyla, $1.3408 \mathrm{E}+21,2.5029 \mathrm{E}+21,1.7895 \mathrm{E}+21$ ve $1.1802 \mathrm{E}+22 \mathrm{dk}^{-1}$ 'dir. Bu değerlerin ortalaması olarak F1.65 reaksiyon mekanizması için ortalama $A$ değeri $5.9133 \mathrm{E}+21$ $\mathrm{dk}^{-1}$ dir. Üçüncü basamakta $5,10,20$ ve $40^{\circ} \mathrm{C} / \mathrm{dk} 1 \mathrm{sitma}$ hızlarındaki D5 reaksiyon mekanizmaları için hesaplanan $E_{\mathrm{a}}$ değerleri sirasıyla, 203.5, 219.6, 222.0 ve $234.2 \mathrm{~kJ} / \mathrm{mol}$ (Tablo 8) olup, bu değerlerin ortalaması $219.8 \mathrm{~kJ} / \mathrm{mol}$ 'dür. Yine üçüncü basamakta, yukarıda belirtilen ısıtma hızlarında hesaplanan $A$ değerleri sirasiyla $1.5559 \mathrm{E}+15,2.7095 \mathrm{E}+16$, $3.8102 \mathrm{E}+16$ ve $3.1045 \mathrm{E}+17 \mathrm{dk}^{-1}$ olup, D5 reaksiyon mekanizması için hesaplanan ortalama $A$ değeri $9.4301 \mathrm{E}+16$ $\mathrm{dk}^{-1}$ olmuştur.
Coats-Redfern yöntemiyle elde edilen ortalama $E_{\mathrm{a}}$ değerleri, model içermeyen yöntemlerden elde edilen ortalama $E_{\mathrm{a}}$ değerleri ile kıyaslandığında, Coats-Redfern sonuçlarının ikinci ve üçüncü basamaklar için sırasıyla ortalama $\sim \% 61$ ve $\sim \% 32$ daha yüksek olduğu görülmektedir. Kinetik yöntemlerde kullanılan denklemlerin türetilmesi esnasında farklı yaklaşım ve sadeleştirmeler uygulandığından sonuçların farklılık göstermesi beklenmektedir, ancak yine de, özellikle ikinci basamak için hesaplanan farkın oldukça yüksek olması dikkat çekmektedir. Coats-Redfern yöntemiyle elde edilen üçüncü basamak ortalama $E_{\text {a }}$ değeri, model içermeyen yöntemlerde olduğu gibi, ikinci basamak ortalama $E_{\mathrm{a}}$ değerinden büyüktür ve Bölüm 3.3.1'de yapılan açıklama burada da geçerlidir. 
Tablo 9. $10^{\circ} \mathrm{C} / \mathrm{dk}$ 1sıtma hızında FWO, KAS ve Starink yöntemlerinden elde edilen $E_{\text {a }}$ değerleri kullanılarak hesaplanan termodinamik özellikler

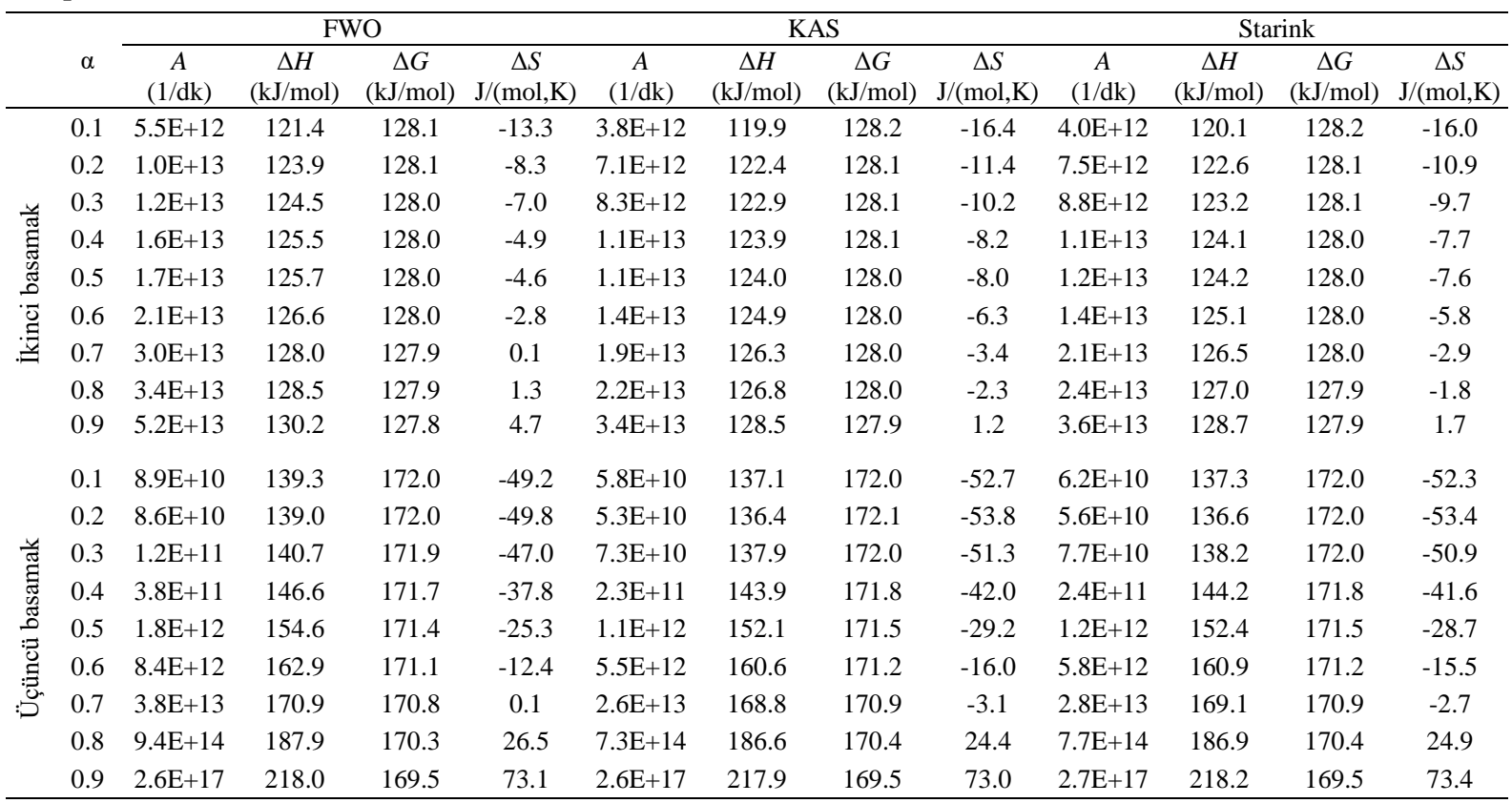

Bu çalışmada, FWO, KAS, Starink ve Coats-Redfern yöntemleriyle kavun çekirdeklerinin ikinci ve üçüncü aktif piroliz basamakları için hesaplanan $E_{\mathrm{a}}$ değerleri sırasıyla, $123.9-215.5$ ve $141.9-234.2 \mathrm{~kJ} / \mathrm{mol}$ aralıklarındadır. Aktif piroliz basamaklarında temel olarak 1sıl bozunmaya uğrayan bileşenler hemiselüloz ve selülozdur. Bu bileşenler için önceki çalışmalarda hesaplanmış $E_{\mathrm{a}}$ değerleri ise sırasıyla, 34 - 179 ve 114 - 288 kJ/mol aralığındadır. Ayrıca, benzer şekilde lignin için hesaplanan $E_{\mathrm{a}}$ değerlerinin 7-226 kJ/mol değerleri arasında olduğu bilinmektedir [49]. Bu nedenle, mevcut çalışmada hesaplanan $E_{\mathrm{a}}$ değerlerinin, biyokütleyi oluşturan temel bileşenlerin $E_{\mathrm{a}}$ değerleriyle uyumlu değerlerde olduğu belirlenmiştir.

\subsection{Termodinamik özelliklerin hesaplanması}

Kavun çekirdeğinin $10^{\circ} \mathrm{C} / \mathrm{dk} \quad 1$ sitma hızındaki termogravimetrik piroliz prosesi için termodinamik özellikler $(\Delta H, \Delta G$ ve $\Delta S)$ FWO, KAS ve Starink yöntemleriyle her iki aktif piroliz basamağı için de 0.1-0.9 aralığındaki dönüșüm değerlerinde belirlenen $E_{\text {a }}$ değerleri üzerinden Denklem (12-15) kullanılarak hesaplanmış ve elde edilen sonuçlar Tablo 9'da verilmiştir. Aktif piroliz basamakları için üç yöntemle hesaplanan termodinamik özellik değerlerinin birbiriyle uyumlu olduğu bu tablodan görülebilmektedir.

Entalpi, bir sistemin toplam 1s1 içeriğini gösteren termodinamik özelliktir. Aktif piroliz basamakları için hesaplanan tüm $\Delta H$ değerleri pozitiftir ve bu durum piroliz reaksiyonlarının 1sı alarak gerçekleştiğini yani endotermik olduğunu belirtmektedir. Her iki basamakta da dönüşüm $\operatorname{arttıkça~} \Delta H$ değerlerinin artış göstermesi, piroliz prosesi ilerledikçe 1S1 girdisinin, yani endotermikliğin artışını belirtmektedir. Ayrıca, literatürde [50] dönüşüm değerlerindeki $E_{\mathrm{a}}$ ve $\Delta H$ farklarının düşük olmasının aktifleşmiş kompleks oluşumunu desteklediği raporlanmıştır. $\mathrm{Bu}$ çalışmada, tüm model içermeyen yöntemlere dayalı yapılan hesaplamalarda ikinci ve üçüncü basamaklar için bu fark, $4.0-4.4$ ve $4.8-5.8 \mathrm{~kJ} / \mathrm{mol}$ değerleri arasındadır. Farkın düşük olması, reaktanların ürüne daha kolay dönüştürüleceğini ifade etmektedir [51].

Gibbs (serbest) enerjisi, dengeyi ya da bir reaksiyonun belirli bir yönde ilerleme eğilimini tanımlamaya yarayan termodinamik özelliktir. İkinci ve üçüncü basamaklar için hesaplanan tüm $\Delta G$ değerleri, sıfırdan oldukça büyük pozitif değerlerdir. Bu durumda, her iki basamaktaki piroliz reaksiyonlarının spontane bir biçimde gerçekleşmeyeceğini, reaksiyonların gerçekleşmesi için enerji girdisine ihtiyaç olduğunu işaret etmektedir. Yüksek $\Delta G$ değeri, reaksiyona daha düşük elverişliliği ve prosesi sürdürmek için daha fazla enerji gerektiği anlamına gelir [52]. Aktif piroliz basamakları için tüm yöntemlerle hesaplanan $\Delta G$ değerlerinin dönüşüm arttıkça çok az düşüşler göstermişse de, hemen hemen sabit kaldığı söylenebilir. Bu da, dönüşüm arttıkça reaksiyonların gerçekleşmesi için gerekli enerji girdisinde belirgin bir değişim olmadığına işaret etmektedir.

Entropi, bir sistemde düzensizliğin ölçüsünü, moleküler düzeyde olası farklı parçacık ve enerji konumlandırma düzenlemelerinin çeşitliliğini ifade eden termodinamik özelliktir. Aktif piroliz basamakları için tüm yöntemlerle hesaplanan $\Delta S$ değerleri yaklaşık olarak $\alpha \leq 0.7-0.9$ değerleri için negatif, daha yüksek dönüşüm değerlerinde ise pozitif değerler almıştır. $\Delta S^{\prime}$ 'in negatif değerleri piroliz esnasında bağların kopmasıyla oluşan ürünlerdeki düzensizliğin başlangıçtaki reaktanların düzensizliğine göre daha düşük olduğunu göstermektedir [50]. Negatif $\Delta S$ değerlerinin, 1sıl dengenin sağlandığını ve ısıl olarak kararlı bir ürünün üretildiğini gösterdiği [53]; yüksek $\Delta S$ değerlerinin ise, termodinamik dengeden uzakta olunduğunu ve reaktifliğin 
yüksek olduğunu gösterdiği belirtilmektedir [41]. Bu bağlamda, özellikle üçüncü bölgenin $\alpha=0.8-0.9$ değerlerinde entropi değişiminin büyük değerlere sahip olması henüz termodinamik dengenin sağlanmadığını işaret etmektedir. Bu durum, Bölüm 3.3.1'de, üçüncü basamakta tüm model içermeyen yöntemlerde $\alpha=0.9$ değerinde gözlenen yüksek $E_{\text {a }}$ değerlerinin, çar ara ürünlerinin stabilize edilmesi için yüksek enerji ihtiyacının varlığını işaret ettiği şeklinde yapılan yorumla paralel niteliktedir.

\section{Sonuçlar}

Bu çalışmada, kavun çekirdeklerinin pirolizi izotermal olmayan termogravimetrik analiz yöntemiyle çalışılmıştır. Çalışmalar, piroliz prosesinin nem ve düşük molekül ağırlıklı moleküllerin uzaklaştırıldığ sırasıyla, temel olarak hemiselüloz, hemiselüloz + selüloz ve ligninin 1sıl bozunmaya uğradığı ikinci, üçüncü ve dördüncü basamaklar olmak üzere dört basamaktan oluştuğunu göstermiştir. Aktif piroliz basamakları en yüksek kütle kaybı hızlarının gözlendiği ikinci ve üçüncü basamaklardır. Aktif piroliz basamakları $\sim 460^{\circ} \mathrm{C}$ 'de sonlanmaktadır ve bu sıcaklıkta uçucu madde olarak, birinci basamak hariç, \%67.3 kütle kaybı gerçekleşmiştir.

Kavun çekirdeklerinin çoğu biyokütle maddeye kiyasla, daha yüksek $\mathrm{C}$ ve $\mathrm{H}$ içeriğgine ve belirgin bir biçimde düşük $\mathrm{O}$ içeriğine sahip olduğu belirlenmiştir. Bu durum, özellikle siv1 yakıt üretimini hedefleyen piroliz prosesleri açısından önemli bir avantaj olarak yorumlanabilir. Ancak, diğer taraftan özellikle N içeriğinin birçok biyokütle maddeye göre belirgin bir biçimde yüksek olması çevresel açıdan dezavantaj oluşturma potansiyeline sahiptir.

Aktif piroliz basamaklarının kinetik parametreleri model içermeyen FWO, KAS, Starink ve model bazlı CoatsRedfern kinetik yöntemleriyle hesaplanmıştır. Bulunan aktivasyon enerjisi değerleri kavun çekirdeklerinin temel organik bileşenleri olan hemiselüloz, selüloz ve ligninin literatürde rapor edilmiş olan değer aralıklarına denk düşmektedir. Coats-Redfern yöntemi kapsamında yapılan hesaplamalar, ikinci ve üçüncü basamaklardaki reaksiyon mekanizmalarının sirasıyla, F1.65 ve D5 olduğunu göstermiştir. Ayrıca, model içermeyen kinetik yöntemlerde elde edilen sonuçlar kullanılarak entalpi, entropi ve Gibbs enerji değişimleri de hesaplanmıştır. Kavun çekirdekleri piroliz prosesi ile değerli ve sürdürülebilir enerji kaynağı olarak değerlendirilme potansiyeline sahiptir ve bu çalışmanın sonuçları, kavun çekirdeği piroliz proseslerinin tasarlanmasına katkı sağlayarak faydalı olacaktır.

\section{Teşekkür}

Yazarlar, kavun çekirdeklerinin öğütülmesi ve fraksiyonlanmasındaki yardımları için Prof. Dr. Aysel Kantürk Figen ve Doç. Dr. Eren Figen'e teşekkürlerini sunar.

\section{Çıkar çatışması}

Yazarlar çıkar çatışması olmadığını beyan etmektedir.

\section{Benzerlik oranı (iThenticate): $\% 7$}

\section{Kaynaklar}

[1] C. A. Bermúdez, J. Porteiro, L. G. Varela, S. Chapela and D. Patiño, Three-dimensional CFD simulation of a large-scale grate-fired biomass furnace. Fuel Processing Technology, 198, 106219, 1-15, 2020. https://doi.org/10.1016/j.fuproc.2019.106219

[2] S. Y. Kan, B. Chen, X. F. Wu, Z. M. Chen and G. Q. Chen, Natural gas overview for world economy: From primary supply to final demand via global supply chains. Energy Policy, 124, 215-225, 2019. https://doi.org/10.1016/j.enpol.2018.10.002

[3] J. Hu, B. Jiang, J. Wang, Y. Qiao, T. Zuo, Y. Sun and $\mathrm{X}$. Jiang, Physicochemical characteristics and pyrolysis performance of corn stalk torrefied in aqueous ammonia by microwave heating. Bioresource Technology, 274, 83-88, 2019. https://doi.org/ 10.1016/j.biortech.2018.11.076

[4] Q. Zhang, Q. Li, L. Zhang, Z. Yu, X. Jing, Z. Wang, Y. Fang and W. Huang, Experimental study on copyrolysis and gasification of biomass with deoiled asphalt. Energy, 134, 301-310, 2017. https://doi.org/ 10.1016/j.energy.2017.05.157

[5] K. Li, L. Zhang, L. Zhu and X. Zhu, Comparative study on pyrolysis of lignocellulosic and algal biomass using pyrolysis-gas chromatography/mass spectrometry. Bioresource Technology, 234, 48-52, 2017. https://doi.org/10.1016/j.biortech.2017.03.014

[6] S. Sobek and S. Werl,. Kinetic modelling of waste wood devolatilization during pyrolysis based on thermogravimetric data and solar pyrolysis reactor performance. Fuel, 261, 116459, 1-15, 2020. https://doi.org/10.1016/j.fuel.2019.116459

[7] G. Mishra, J. Kumar and T. Bhaskar. Kinetic studies on the pyrolysis of pinewood. Bioresource Technology, 182, 282-288, 2015. https://doi.org/10.1016/j.biortech. 2015.01.087

[8] N. Ertaş and M. Aslan, A study on the potential of using melon wastes in biscuit production. Kahramanmaraş Sütçü İmam Üniversitesi Tarım ve Doğa Dergisi, 23 (5), 1216-1224, 2020. https://doi.org/10.18016/ ksutarimdoga.vi.681812

[9] FAO, Food and Agriculture Organization of United Nations, FAOSTAT, Crops, Cherries. http://www.fao.org/faostat/en/\#data/QC . Accessed: 21 January 2021.

[10] M. Ünlü, R. Kurum ve A. Ünlü, Örtüaltı kavun (Cucumis melo ssp. melo) yetiştiriciliği için geliştirilen hibritlerin verim ve meyve bakımından değerlendirilmesi. Akademik Ziraat Dergisi, 6, 121126, 2017. https://dergipark.org.tr/tr/pub/azd/issue/ $32275 / 363353$

[11] A. Ahmed, E. A. Afolabi, M. U. Garba, U. Musa, M. Alhassan and K. Ishaq, Effect of particle size on thermal decomposition and devolatilization kinetics of melon seed shell. Chemical Engineering Communications, 206(9), 1228-1240, 2019. https://doi.org/10.1080/00986445.2018.1555530

[12] B. B. Nyakuma, F. Roozbahani, O. Oladokun, Y. A. Dodo, A. S. Elnafaty and T. John-Paul Ivase, Kinetic analysis of melon seed husk using non-isothermal thermogravimetric analysis. Materials Today: 
Proceedings, 5, 11(2), 23249-23257, 2018 https://doi.org/10.1016/j.matpr.2018.11.057

[13] Ş. Bayram and E. Güneş, Nutrients and cucurbita eaten from the seed. International Journal of Environmental Pollution and Environmental Modelling, 3 (1), 27-33, 2020. https://dergipark.org.tr/tr/pub/ijepem/issue/ 54371/789209

[14] S. Sabanc1, C. Celebi and F. Icier, Rheological properties of sübye. traditional beverage. Akademik G1da, 12 (1), 11-15, 2014. https://dergipark.org.tr/ tr/download/article-file/1186530

[15] İ. Çelik ve Y. Kuzumoğlu, Farklı tane unları ve çekirdek tozları kullanılarak glutensiz lokma tatlısı üretimi ve kalite özellikleri. Akademik Gıda, 18 (2), 156-163, 2020. https://dergipark.org.tr/tr/pub /akademik-gida/issue/55310/758828

[16] İ. Çelik ve K. Pozan, Kavun çekirdeği tozunun eriştenin bazı özelliklerine etkisi. Gıda, 45 (5), 907-916, 2020. https://dergipark.org.tr/tr/pub/gida/issue/56397/70062 7

[17] T. Xu, F. Xu, Z. Hu, Z. Chen and B. Xiao, Nonisothermal kinetics of biomass-pyrolysis-derived-tar (BPDT) thermal decomposition via thermogravimetric analysis. Energy Conversion and Management, 138, 452-460, 2017. https://doi.org/10.1016/j.enconman. 2017.02.013

[18] Th. Damartzis, D. Vamvuka, S. Sfakiotakis and A. Zabaniotou, Thermal degradation studies and kinetic modeling of cardoon (Cynara cardunculus) pyrolysis using thermogravimetric analysis (TGA). Bioresource Technology, 102, 6230-6238, 2011. https://doi.org/ 10.1016/ j.biortech.2011.02.060

[19] A. A. Jain, A. Mehra and V. V. Ranade, Processing of TGA data: Analysis of isoconversional and model fitting methods. Fuel, 165, 490-498, 2016. https://doi.org/10.1016/j.fuel.2015.10.042

[20] G. Chen, S. He, Z. Cheng, Y. Guan, B. Yan, W. Ma and D. Y. C. Leung, Comparison of kinetic analysis methods in thermal decomposition of cattle manure by themogravimetric analysis. Bioresource Technology, 243, 69-77, 2017. https://doi.org/10.1016/j.biortech. 2017.06.007

[21] S. O. Giwa and T. O. Akanbi, A review on food uses and the prospect of egusi melon for biodiesel production. Bioenergy Research, 13, 1031-1045, 2020. https://doi.org/10.1007/s12155-020-10145-4

[22] B. B. Nyakuma, Thermogravimetric and kinetic analysis of melon (Citrullus colocynthis 1.) seed husk using the distributed activation energy model. Environmental and Climate Technologies, 15 (1), 77 89, 2015. https://doi.org/10.1515/rtuect-2015-0007

[23] K. Açıkalın, Thermogravimetric analysis of walnut shell as pyrolysis feedstock. Journal of Thermal Analysis and Calorimetry, 105, 145-150, 2011. https://doi.org/10.1007/s10973-010-1267-x

[24] K. Açıkalın, Pyrolytic characteristics and kinetics of pistachio shell by thermogravimetric analysis. Journal of Thermal Analysis and Calorimetry, 109, 227-235, 2012. https://doi.org/10.1007/s10973-011-1714-3
[25] G. Gözke and K. Açıkalın, Pyrolysis characteristics and kinetics of sour cherry stalk and flesh via thermogravimetric analysis using isoconversional methods. Journal of Thermal Analysis and Calorimetry, 2020. https://doi.org/10.1007/s10973-020-10055-9

[26] M. R. B. Guerrero, M. M. d.S. Paula, M. M. Zaragoza, J. S. Gutiérrez, V. G. Velderrain, A. L. Ortiz and V. Collins-Martínez, Thermogravimetric study on the pyrolysis kinetics of apple pomace as waste biomass. International Journal of Hydrogen Energy, 39, 16619 16627, 2014. https://doi.org/10.1016/j.ijhydene. 2014.06.012

[27] S. S. Tuly, M. Parveen, M. R. Islam, M. S. Rahman and H. Haniu, Pyrolysis kinetics study of three biomass solid wastes for thermochemical conversion into liquid fuels. AIP Conference Proceedings, 1851, 020083, 2017. http://dx.doi.org/10.1063/1.4984712

[28] C. Gai, Y. Dong and T. Zhang, The kinetic analysis of the pyrolysis of agricultural residue under nonisothermal conditions. Bioresource Technology, 127, 298-305, 2013. https://doi.org/10.1016/ j.biortech.2012.09.089

[29] W. Gao, K. Chen, J. Zeng, J. Xu and B. Wang, Thermal pyrolysis characteristics of macroalgae Cladophora glomerata. Bioresource Technology, 243, 212-217, 2017. https://doi.org/10.1016/j.biortech.2017.06.041

[30] M. J. B. Fong, A. C. M. Loy, B. L. F. Chin, M. K. Lam, S. Yusup and Z. A. Jawad, Catalytic pyrolysis of Chlorella vulgaris: Kinetic and Thermodynamic analysis. Bioresource Technology, 289, 121689, 1-10, 2019. https://doi.org/10.1016/j.biortech.2019.121689

[31] L. Luo, X. Guo, Z. Zhang, M. Chai, M. Rahman, X. Zhang and J. Cai, Insight into pyrolysis kinetics of lignocellulosic biomass: 1soconversional kinetic analysis by the modified friedman method. Energy Fuels, 34 (4), 4874-4881, 2020. https://doi.org/ 10.1021/acs.energyfuels.0c00275

[32] Q. V. Bach and W. H. Chen, Pyrolysis characteristics and kinetics of microalgae via thermogravimetric analysis (TGA): A state-of-the-art review. Bioresource Technology, 246, 88-100, 2017. https://doi.org/ 10.1016/j.biortech.2017.06.087

[33] H. Huang, J. Liu, H. Liu, F. Evrendilek and M. Buyukada, Pyrolysis of water hyacinth biomass parts: Bioenergy. gas emissions. and by-products using TGFTIR and Py-GS/MS analyses. Energy Conversion and Management, 207, 112552, 1-14, 2020. https://doi.org/ 10.1016/j.enconman.2020.112552

[34] M. A. Mehmood, M. S. Ahmad, Q. Liu, C. G. Liu, M. H. Tahir, A. A. Aloqbi, N. I. Tarbiah, H. M. Alsufiani and M. Gull, Helianthus tuberosus as a promising feedstock for bioenergy and chemicals appraised through pyrolysis. kinetics. and TG-FTIR-MS based study. Energy Conversion and Management, 194, 37 45, 2019. https://doi.org/10.1016/j.enconman. 2019.04.076

[35] G. Ye, H. Luo, Z. Ren, M. S. Ahmad, C. G. Liu, A. Tawab, A. B. Al-Ghafari, U. Omar, M. Gull and M. A. Mehmood, Evaluating the bioenergy potential of 
Chinese liquor-industry waste through pyrolysis. thermogravimetric. kinetics and evolved gas analyses. Energy Conversion and Management, 163, 13-21, 2018. https://doi.org/10.1016/j.enconman.2018.02.049

[36] Y. He, C. Chang, P. Li, X. Han, H. Li, S. Fang, J. Chen and X. Ma, Thermal decomposition and kinetics of coal and fermented cornstalk using thermogravimetric analysis. Bioresource Technology, 259, 294-303, 2018. https://doi.org/10.1016/j.biortech.2018.03.043

[37] Y. Qiao, B. Wang, P. Zong, Y. Tian, F. Xu, D. Li, F. Li and Y. Tian, Thermal behavior, kinetics and fast pyrolysis characteristics of palm oil: Analytical TGFTIR and Py-GC/MS study. Energy Conversion and Management, 199, 111964, 1-10, 2019. https://doi.org/ 10.1016/j.enconman.2019.111964

[38] M. Jeguirim, J. Bikai, Y. Elmay, L. Limousy and E. Njeugna, Thermal characterization and pyrolysis kinetics of tropical biomass feedstocks for energy recovery. Energy for Sustainable Development, 23, 188-193, 2014. https://doi.org/10.1016/j.esd. 2014.09.009

[39] D. Trache, A. Abdelaziz and B. Siouani, A simple and linear isoconversional method to determine the preexponential factors and the mathematical reaction mechanism functions. Journal of Thermal Analysis and Calorimetry, 128, 335-348, 2017. https://doi.org/ 10.1007/s10973-016-5962-0

[40] S. Vyazovkin, Isoconversional Kinetics of Thermally Stimulated Processes. Springer International Publishing, Switzerland, 2015.

[41] A. A. D. Maia and L. C. De Morais, Kinetic parameters of red pepper waste as biomass to solid biofuel. Bioresource Technology, 204, 157-163, 2016. http://dx.doi.org/10.1016/j.biortech.2015.12.055

[42] M. Radojević, B. Janković, V. Jovanović, D. Stojiljković and N. Manić. Comparative pyrolysis kinetics of various biomasses based on model-free and DAEM approaches improved with numerical optimization procedure. PLoS ONE, 13(10), e0206657, 1-25, 2018. https://doi.org/10.1371/journal.pone. 0206657

[43] F. Rego, A. P. S. Dias, M. Casquilho, F. C. Rosa and A. Rodrigues. Pyrolysis kinetics of short rotation coppice poplar biomass. Energy, 207, 118191, 1-9, 2020. https://doi.org/10.1016/j.energy.2020.118191

[44] M. Zhai, L. Guo, Y. Zhang, P. Dong, G. Qi and Y. Huang, Kinetic parameters of biomass pyrolysis by TGA. BioResources, 11(4), 8548-8557, 2016. https://bioresources.cnr.ncsu.edu/resources/kineticparameters-of-biomass-pyrolysis-by-tga/

[45] J. Zhang, J. Liu, F. Evrendilek, X. Zhang and M. Buyukada, TG-FTIR and Py-GC/MS analyses of pyrolysis behaviors and products of cattle manure in $\mathrm{CO}_{2}$ and $\mathrm{N}_{2}$ atmospheres: Kinetic. thermodynamic. and machine-learning models. Energy Conversion and Management, 195, 346-359, 2019. https://doi.org/ 10.1016/j.enconman.2019.05.019

[46] Y. Qiao, B. Wang, Y. Ji, F. Xu, P. Zong, J. Zhang and Y. Tian, Thermal decomposition of castor oil. corn starch. soy protein. lignin. xylan. and cellulose during fast pyrolysis. Bioresource Technology, 278, 287-295, 2019. https://doi.org/10.1016/j.biortech.2019.01.102

[47] Y. M. Kim, J. Jae, H. W. Lee, T. U. Han, H. Lee, S. H. Park, S. Kim, C. Watanabe and Y. -K. Park, Ex-situ catalytic pyrolysis of citrus fruit peels over mesoporous MFI and Al-MCM-41. Energy Conversion and Management, 125, 277-289, 2016. https://doi.org/ 10.1016/j.enconman.2016.02.065

[48] S. Vyazovkin, A. K. Burnham, J. M. Criado, L. A. Pérez-Naqueda, C. Popescu and N. Sbirrazzuoli, ICTAC Kinetics Committee recommendations for performing kinetic computations on thermal analysis data. Thermochimica Acta, 520, 1-19, 2011. https://doi.org/10.1016/j.tca.2011.03.034

[49] A. Anca-Couce, C. Tsekos, S. Retschitzegger, F. Zimbardi, A. Funke, S. Banks, T. Kraia, P. Marques, R. Scharler, W. de Jong and N. Kienzl, Biomass pyrolysis TGA assessment with an international round robin. Fuel, 276, 118002, 1-16, 2020. https://doi.org/10.1016/ j.fuel.2020.118002

[50] R. Kaur, P. Gera, M. K. Jha and T. Bhaskar, Pyrolysis kinetics and thermodynamic parameters of castor (Ricinus communis) residue using thermogravimetric analysis. Bioresource Technology, 250, 422-428, 2018. https://doi.org/10.1016/j.biortech.2017.11.077

[51] X. Xu, R. Pan, P. Li and R. Chen, Kinetics. thermodynamics and volatile products of Camphorwood pyrolysis in inert atmosphere. Applied Biochemistry and Biotechnology, 191, 1605-1623, 2020. https://doi.org/10.1007/s12010-020-03300-2

[52] J. Huang, J. Liu, J. Chen, W. Xie, J. Kuo, X. Lu, K. Chang, S. Wen, G. Sun, H. Cai, M. Buyukada and F. Evrendilek, Combustion behaviors of spent mushroom substrate using TG-MS and TG-FTIR: Thermal conversion. kinetic. thermodynamic and emission analyses. Bioresource Technology, 266, 389-397, 2018. https://doi.org/10.1016/j.biortech.2018.06.106

[53] A. Shahid, M. Ishfaq, M. S. Ahmad, S. Malik, M. Farooq, Z. Hui, A. H. Batawi, M. E. Shafi, A. A. Aloqbi, M. Gull and M. A. Mehmood, Bioenergy potential of the residual microalgal biomass produced in city wastewater assessed through pyrolysis, kinetics and thermodynamics study to design algal biorefinery. Bioresource Technology, 289, 121701, 2019. https://doi.org/10.1016/j.biortech.2019.121701 